\title{
Towards a multi-dimensional methodology supporting a safeguarding decision on the future access to mineral resources
}

\author{
A. Mateus ${ }^{1,2} \cdot$ C. Lopes $^{1} \cdot$ L. Martins ${ }^{3} \cdot$ J. Carvalho $^{4}$
}

Received: 20 April 2017 / Accepted: 24 July 2017 / Published online: 9 August 2017

(C) The Author(s) 2017. This article is an open access publication

\begin{abstract}
A multi-dimensional methodology is proposed to delimit areas hosting mineral resources of public importance (MRoPI). The assessment procedure considers the Level of Geological Knowledge ( $L G K$ ) along with the Economic (Ec), Environmental (Ev) and Social Development and Acceptance (SDA) dimensions. Different sets of independent, but complementary and variably weighed, criteria support the appraisal of each dimension, and a final score $\left(M R o P I_{r}\right)$ results from a reasonable balance between $L G K$ and $(E c+E v+S D A)$. A ranking based on $M R o P I_{r}$ will fall in the $[1,10]$ interval, as imposed by the scaling normalising factor, but only specific tracts having $M R O P I_{r} \geq 4$ display $L G K$ values confident enough to be covered by a safeguarding decision at a given time. Adequate $M R o P I_{r}$ mapping can also be done, interpolating within the kriging formalism and evaluating thoroughly the modelling results until
\end{abstract}

Electronic supplementary material The online version of this article (doi:10.1007/s13563-017-0114-y) contains supplementary material, which is available to authorized users.

A. Mateus

amateus@ fc.ul.pt

1 Departamento de Geologia, Faculdade de Ciências da Universidade de Lisboa, Ed. C6, Piso 4, Campo Grande,

1749-016 Lisbon, Portugal

2 Instituto Dom Luíz (IDL), Ed. C1, Piso 1, Campo Grande, 1749-016 Lisbon, Portugal

3 ASSIMAGRA, Rua Aristides de Sousa Mendes n³B, 1600-412 Lisbon, Portugal

4 Laboratório Nacional de Energia e Geologia (LNEG), Ap.7586, 2720-866, Amadora, Portugal achieving the final map. The methodology application shows in addition that the combined use of $L G K, E c, E v$ and $S D A$ allows to address suitably two overlapping and coexisting, although different, issues: (1) safeguarding the future access to mineral resources and (2) planning the mineral development in the short-medium term, recognising the need of assigning specific areas to mining activities.

Keywords Mineral resources · Public importance .

Safeguarding $\cdot$ Multi-dimensional methodology $\cdot$ Kriging interpolation · Portuguese "base metals" resources

\section{Introduction}

The present need to ensure a continued supply of an increasingly high number of mineral products is well documented (e.g. Arndt and Ganino, 2012). In future, the expected demand in minerals by Society should enlarge, namely if the desirable paths to Human Civilization Sustainability were in fact fulfilled, generating intra- and inter-generational balanced levels of equity and prosperity (e.g. Behrens et al., 2007; Giljum et al., 2008; Krausmann et al., 2009; Mudd, 2010; Bloodworth and Gunn, 2012; Costa e Silva, 2015). Part of this growth in minerals demanding is related to the anticipated expansion of new consumers in emerging economies $(\approx 3$ billion more by ca. 2030; United Nations, 2015). However, if the current political and economic drivers continue and the foreseen megatrends are confirmed, the large variety and incessantly rising quantities of minerals-derived components required for low-C technologies, energy storage and digital services will put additional pressure on markets, boosting the risk 
of supply disruption (e.g. Erdmann and Graedel, 2011; Zhanheng, 2011; Peiró et al., 2013; Roelich et al., 2014; Goe and Gaustad 2014; Baldi et al., 2014). This risk will not be the same for all minerals and their derivatives, but for sure it will not affect only the "high-tech" metals ${ }^{1}$ characterised by (so far) limited recycling, deficient knowledge of their resources/reserves (often exploited as by- or co-products) and confined production to few regions (e.g. Nassar et al., 2011; Graedel et al., 2012; Fizaine, 2013; Massari and Ruberti, 2013). On the contrary, as far as can be numerically projected, the supply risks are expected for a quite large number of mineral products, many of them presently provided by active exploitation of easily accessible, but non-inexhaustible, rock masses, natural accumulations of sediments, or even high-grade/high-tonnage ores (e.g. Rosenau-Tornow et al., 2009; Prior et al., 2013; Vidal et al., 2013; Graedel and Nassar, 2013; Achzet and Helbig, 2013; Nuss et al., 2014; Glöser et al., 2015).

Mitigation of the supply risk for a significant number of mineral products can be attained by searching the adequate mixing of sources in each time, facing the existing needs and involving various proportions of products derived from exploitation of primary and secondary resources, along with urban mining (here including recycling) and the search of economically feasible substitutes. However, as clearly demonstrated in various studies (e.g. Geyer and Jackson, 2004; Pagell et al., 2007; Bloodworth and Gunn, 2012; Binnemans et al., 2013), the "urban resource" will always be minor compared to the amounts needed to meet the foreseen increase in minerals demand, even in presence of improved rates in collecting systems. In addition, substitution rates are too slow and successful paths for their completeness hardly predictable since the quest may suddenly become obsolete by the arrival of new materials, innovative products, changes in customer needs, successful (and of lower cost) recycling techniques and discovery of new resources that may provide the mineral product that is intended to be replaced at competitive prices (e.g. Porter and van der Linde, 1995; Ashby, 2000; Edwards, 2004, Purba Rao, 2005; Rosenau-Tornow et al., 2009; Erdmann and Graedel, 2011; Templelman, 2011). So, the future supply of mineral products to the Society will continue to depend on mining planning and, accordingly, on the long-term availability of primary mineral resources. This dependence will not be the same for all mineral products, nor will be equally recorded over time; but its share should always be considered, irrespective of the adopted model of economic development (e.g. Costa e Silva, 2015). Consequently, safeguarding the current and future access to mineral resources is one of the foremost challenges that the Society has to face with realism, requiring for that purpose well-grounded and transparent decisions.

\footnotetext{
${ }^{1}$ The term refers to all metals, usually rare in abundance, essential for the production of high-technology devices and engineered systems.
}

Concerns with the physical exhaustion are also recurrent when the future access to mineral resources is discussed. Many lines of evidence show that physical exhaustion of primary resources is unlikely (e.g. Bloodworth and Gunn, 2012; Graedel and Nassar, 2013), but common geological perception also proves convincingly that the average elemental mass in any natural geochemical reservoir is not uniformly distributed, demonstrating furthermore that particular attributes of sediments, rocks and ores are related to specific, sometimes subtle, features triggered by a succession of events that trace the geodynamic evolution of a given region (e.g. Robb, 2005; Arndt et al., 2017). Therefore, primary mineral products have to be exploited where the confirmed geological continuity attests the existence of economically viable resources, whose proper validation involves, most often, large intensive investments for long time frames. This means that identified, currently non-economic and/or not yet enough studied, resources and promising targets should be safeguarded in addition to known mineral deposits; and because improvements in geological knowledge and consequential insights into exploration surveys are, by definition, a never-ending processes, safeguarded areas should be periodically revisited. Once again, these appraisals must follow a series of principles, hopefully assisting well-grounded and transparent decisions.

The long-term availability of mineral resources depends strongly on the implementation of measures for safeguarding the access to them (e.g. Hodges, 1995; Tiess, 2010; Scholz and Wellmer, 2013; Arndt et al., 2017). So, the location of sites where mineral exploration and exploitation occurs or can take place should be considered in all (multi-scale) landuse plans by increasing significantly the levels of consultation between land-use planning and mining Authorities, involving as well other relevant players at local, regional or national levels (e.g. Hilson, 2002; Wrighton et al., 2014). This implies also that land-use planners must be aware about the geological characteristics of the land that they are planning, fully recognising that: (1) places where exploration and mining may occur are limited, unlike many other land uses; and (2) mineral exploration and extraction represents a temporary use of land, allowing the design of various land-use options after ceasing the exploitation and depending on the nature of the mining activity and the extent to which planning for the postclosure phase takes place (e.g. Carranza et al., 1999; De Groot, 2006; Kesler and Simon, 2015). The reconciliation task represents a major challenge, but difficulties will be minor and the objectives achieved if the whole process could be steadily improved and assisted by a methodology recognised as credible by all the entities involved in land-use planning, including those dealing with environmental issues and safeguarding of natural diversity and cultural heritage.

In this work, a multi-dimensional methodology to support a safeguarding decision on the future access to mineral resources is proposed and discussed. After briefly address the 
key question on the mineral resources that potentially should be involved in that decision, the criteria used to perform their identification, relative classification and mapping are presented. Geological information supports the mainstay criteria, being complemented (and balanced) by other figures that recognise the multi-dimensionality of environmental, economic and social issues envisaged as inevitable in any modern appraisal on the current and future access to mineral resources; factors backing each criteria are also identified and variably weighed. Application of the methodology to a main example in Portugal is reported, facilitating the understanding of how the procedure should be used and the results interpreted. This represents one of several alternative views developed within the EU's funded MINATURA2020 project (http://minatura2020.eu/) that does not compel the formal opinion of the Project Coordination and associated partners, only committing its authors.

\section{Mineral resources of public interest and/or public importance}

The intended methodology depends primarily on the answer to the following question: what mineral resources should be safeguarded? Only those that, among the already demonstrated resources, are sufficiently characterised to ensure a given volume of reserves with specific attributes? All the inferred and demonstrated mineral resources, irrespectively of the level of knowledge available about each one? Or, from a wider perspective, should the safeguarding decision be extended to areas (in renowned or ill-known mining provinces) that reveal potential to host deposits whose existence is not yet proved? As usual in this kind of issues, a broad range of plausible responses can be obtained, depending on the perspective behind the justification used (or imposed by law) to trigger the "safeguard mechanism".

The most common approach makes use of the "public interest" qualification (e.g. Alexander, 2002; Ho, 2012) according to which the welfare of the public in general resulting from the safeguarded mineral resources must be assured. So, the main reason supporting the safeguarding decision depends on a particular economic benefit or any other type of (measured) advantage that can be obtained in future. As a result, economic-derived thresholds would prevail and only demonstrated resources able to provide acceptable levels of rated welfares would be considered, precluding all others due to: (1) adverse (pre-)feasibility studies; or (2) unfavourable externalities to investment; or (3) absence of enough geological information and/or economic or environmental viability assessments. This perspective, excluding also promising exploration targets, has the great inconvenience of being based on static analyses that hardly respond to future expectations. In other words, by ignoring a large number of resources for circumstantial reasons (valid in a particular time window, but not necessarily in the future), it opens the door to their sterilisation, therefore contributing to enhance the envisaged supply risks of many mineral products. The weakness can be circumvented by imposing less stringent limits to the benefits expected from the "safeguarding decision" or by considering data from out-dated feasibility studies, or even by conceding an exceptionality status to some types of resources; but such kind of adjustments are not always properly understood by communities, often not aware of the critical factors that determine the non-linear dynamic behaviour of mining industry and of raw materials trade.

An alternative approach to support the "safeguarding decision" on the current and future access to mineral resources can be designed by using the "public importance" qualification, which emphasises the public accountability obligation of decision-makers in authority (e.g. Ruggie, 2004; Rowe and Frewer, 2004, 2005; Ho, 2012). This means that, before any decision, a comprehensive analysis of what is intended to safeguard should be done, evaluating in short and longer terms: (1) who would gain what benefits from what the decision-makers propose and (2) who would bear what costs and risks. Therefore, the key factors involved in the "public importance" qualification should be communication, transparency and responsible engagement of all the concerned stakeholders (governments, municipalities, mining companies, NGOs and local communities). The main advantage of this conceptual alternative is its non-obligation to provide rated welfares of any kind, besides of representing a possible source of minerals in the future. Therefore, none of the identified mineral resources or promising exploration targets is excluded a priori, as long as the available information is sufficiently robust and credible to support the "safeguarding decision" and fully understood by all the concerned stakeholders; so, the existing level of geological knowledge should be decisive both in the categorisation of mineral resources and of the threshold definition for safeguarding purposes. This is noteworthy because we are dealing with the present and future access to mineral resources and not with their (current or foreseen) regional, national or international economic relevance, which relies on natural attributes (tonnage, grade, physical and/or chemical characteristics, etc.) and on the "market behaviour" (particularly, the demand/supply trends - historical, current and projected-safe provision, prices stability, etc.). All these features, quite vulnerable to a large variety of dynamic factors (e.g. Bojarski et al., 2009; Ruberts, 2009; Humphreys, 2010; Chen, 2010; Veld et al., 2011; Batten et al., 2010; Erten and Ocampo, 2012; Gleich et al., 2013; Knoeri et al., 2013), should be used in the appraisal, but solely as complementary criteria.

The use of "public importance" instead of "public interest" qualification has the extra advantage of not require any temporal or particular restrictions related to legal or environmental 
specificities, because the access to mineral deposits should be viewed in parity with other natural resources, including those located in ill-characterised mining provinces or not presenting enough (updated) information to be properly classified according to international reporting code systems, in addition to new discoveries. Therefore, the basic task should focus on suitable criteria to be used in delimiting areas with promising potential to supply mineral products besides others hosting mineral resources with already demonstrated interest. All these meet the basic conditions to be classified as mineral resources of public importance (MRoPI). In this regard, it should be noted that the broader application of the concept mineral resources allows including in the intended assessment (valid for a given time frame): (1) all the deposits with proven or probable mineral reserves; (2) all the known but uneconomic deposits related to measured, indicated or even inferred resources; and (3) all the tracts hosting hypothetical deposits but presenting auspicious (greenfields or brownfields) exploration results.

\section{Methodology}

Considering the rationale behind MRoPI, the intended methodology should seek for the adequate criteria densification able to categorise mineral resources (according to the available geological knowledge), as well as their mapping, after decide about the threshold to be used for that purpose. The results obtained with this exercise should be viewed as a technical-based recommendation for a "safeguarding decision" on the future access to mineral resources.

\section{Guiding principles}

The build-up of criteria densification took into consideration the following guiding principles: comprehensibility (i.e. clear, logical and coherent criteria); defendable (i.e. accountable, transparent and independently validated criteria); consistency (reliable and regular/systematic criteria application); and knowledge-based (i.e. criteria grounded in impartial assessments of the accessible data and/or information). Additionally, the criteria densification was developed in such way that the existing data can be consistently combined, recognising and respecting: (1) the limitations of existent databases, often much fragmented and non-harmonised; (2) the lacking of some data at all scales, thus claiming for criteria enough dynamic (flexible) that may incorporate qualitatively (or semi-quantitatively) some figures that are not currently available in a different way; (3) the minor relevance of several criteria at some scales; (4) the need of apply differently and at different scales criteria that should serve any kind of mineral resources (from various types of ores to different sets of industrial rocks/minerals and ornamental stones); and (5) the need of balance the economic, environmental and social dimensions after a previous (and independent) assessment made on the basis of the available geological information and knowledge. As a result of these constraints, the criteria densification and their application are intrinsically flawed and should be periodically revised because: (1) advances in the geoscientific knowledge, including the systematic revisiting and improvements of exploration models, may foster the identification of new targets (and relevant discoveries); (2) innovative technologies and tools may change significantly some economic and/or environmental appraisals; (3) new markets for mineral products may emerge, thus altering their economic relevance and, ultimately, their criticality status; and (4) considerable (non-circumstantial) changes in prices of mineral products and/or in the Society's needs may occur.

\section{Starting point}

The current starting point is far from the ideal one. However, the existent mineral inventory in each country (optimistically under permanent updating) should be reliable enough to support appropriate mineral policies able to consolidate and enlarge the interest of exploration and mining companies, thus attracting inward investments to exploration/exploitation activities, as well as to added-value transformations of mineral products. This means that the available data provided by the existent mineral inventories should be sufficient, at least in a first instance, to identify and mapping specific tracts for MRoPI assessments, i.e. geographical areas defined by particular geological attributes disclosed either by "point-source" data or by a thoroughly spatial (2D to $3 \mathrm{D}$ ) evaluation of multidisciplinary data. Nonetheless, the current starting point is confronted with various difficulties, namely those caused by (1) databases of variable extension and heterogeneity, covering differently exploration and exploitation results of various ores, industrial rock/minerals and ornamental stones; and (2) quite variable perception of what should be (or not) safeguarded; a reconciliation between what is of "public importance" and of "public interest" should be attempted. In addition, the available information is often limited to isolate and relatively small areas, scattered in a large region. Could we interpolate this kind of information and, if so, under what conditions?

\section{Reasoning behind the MRoPI classification and mapping}

Seeking for a technical-based recommendation supporting a "safeguarding decision" on the future access to mineral resources, the main dimensions involved in that assessment should be identified and weighed according to the intended goals. Since the purpose is to identify mineral resources of public importance, as defined in "Mineral resources of public interest and/or public importance" section, the existing 
geological information on these resources has to be balanced with environmental, economic and social figures, thus including in the assessment procedure comparative appraisals on alternative land uses and related impacts and/or on economic/social benefits. Nonetheless, without adequate knowledge of the mineral resources under evaluation, all the environmental, economic and social figures related to their current or foreseen exploitation are meaningless. Therefore, the geological knowledge is a prerequisite to evaluate the other dimensions and should be considered as decisive, whatever the structure used in the assessment procedure.

Let us denote by LGK the Level of Geological Knowledge that is available for each specific tract (from a cluster of critical outcrops to an area including mineral resources differently evaluated) and its regional setting. The past, ongoing or foreseen exploitation of that specific tract could be assessed by means of a set of criteria pondering equally the Economic $(E c)$, Environmental (Ev) and Social Development and Acceptance (SDA) dimensions. Therefore, a general MRoPI ranking $\left(=M R o P I_{r}\right)$ can be established by means of:

$$
M R o P I_{r}=n L G K+m(E c+E v+S D A)
$$

The empirical parameters $n$ and $m$ are debatable, but considering that the fundamental feature is the safeguarding for future access/use of a mineral resource, $L G K$ should be the prevailing dimension; thus, $n>m$. Furthermore, scaling the range for a maximum value of 10 and assuming $n=5.5$, the resulting $m$ equals 1.5. This means that in an ideal case where each factor is one (i.e. $L G K=E c=E v=S D A=1$ ), the relative and combined weight of the economic $(E c)$, environmental $(E v)$ and social (SDA) dimensions is 4.5:

$$
M R_{0} P I_{r}=5.5+4.5=10
$$

which seems reasonable in comparison with the 5.5 value assigned to $L G K$. The results obtained so far for several types of mineral resources in Portugal (see below) show that the assumptions made either for the weighing equity of $E c, E v$ and $S D A$ dimensions, or for the empirical parameters $n$ and $m$, are plausible. However, alternative views may be used, differentiating the weighs of $E c, E v$ and $S D A$ dimensions and/or the relative balance between the empirical parameters $n$ and $m$.

As originally conceived, equation (1) allows categorise any specific tract in a scale from 1 to 10 , and the $L G K, E c, E v$ and $S D A$ dimensions are assessed by means of a set of independent, but complementary, criteria (see below). Afterwards, having a MRoPI ranking list and intending a MRoPI map, a comprehensive data analysis could be performed seeking for interpolated spatial distributions whose physical meaning must reveal strong consistency with the available geological information at a regional scale. Each map produced will represent no more than a "photogram" for each commodity or industrial rock/mineral, therefore valid for a relatively short time frame and considering the available information at a given time. This stresses the need of recurrently reassess the state-of-the-art in function of updated information, as previously stated, which can be easily harmonised with the periodic revision of land-use plans previewed in modern methods of land-use management and policies.

\section{Criteria densification used in the $M R o P I_{r}$ computation}

Replacing the empirical parameters $n$ and $m$ of equation (1) by 5.5 and 1.5, respectively, the $M R o P I_{r}$ results as:

$M R_{o P I}=5.5 L G K+1.5(E c+E v+S D A)$

Considering now the guiding principles stated in "Guiding principles" section, the $L G K, E c, E v$ and $S D A$ dimensions for each specific tract will be assessed by means of a set of independent, but complementary, criteria. In general terms, this can be expressed as follows:

$$
\begin{aligned}
& L G K=\sum_{i=1}^{n}\left(k_{i} G_{i}\right) Q D A_{i} \\
& E c=\sum_{j=1}^{n}\left(k_{j} E c_{j}\right) Q D A_{j} \\
& E v=\sum_{l=1}^{n}\left(k_{l} E v_{l}\right) Q D A_{l} \\
& S D A=\sum_{w=1}^{n}\left(k_{w} S D A_{w}\right) Q D A_{w}
\end{aligned}
$$

with increasingly higher values of $L G K, E c, E v$ and $S D A$ denoting adding levels of credible data, information and knowledge existing for each specific tract. In equations from (4) to (7), QDA represents a factor of "qualitative data assessment", which equals 1.00 if the data is considered enough to assist the appraisal or 0.00 if there is no data available to support a credible assessment. However, in presence of a well-structured, harmonised and extensive database, $Q D A$ could be densified, distinguishing 4 key scores, as follows: $Q D A=1.00=$ complete and reliable data; $Q D A=0.75=$ reliable, but needing additional data; $Q D A=$ $0.50=$ acceptable, but requiring additional data along with independent validation of the existing one; $Q D A=0.25=$ insufficient data; and $Q D A=0.00=$ no data available to support a credible assessment.

\section{The $L G K$ dimension}

This critical dimension discriminates distinct levels of geological data, information and knowledge at different scales (from 
regional to local), making use of four complementary criteria ( $G_{1}$ to $\left.G_{4}\right)$, each one scored from "Acceptable" $(0.25)$ to "Excellent" (1.00), as shown in Table 1.

The $G_{1}$ criterion accounts for the availability and quality of the background geological information and knowledge, either in known or unknown mining/quarrying districts, thus embracing multiscale regional information on the existent expectations about undiscovered resources (anticipated by updated geological models) and considering as well the general (lithostratigraphic, structural, geochemical, geophysical) data on the hosting environments of identified resources. This means that a complete geological knowledge of the territory should exist, therefore justifying the potential for speculative to hypothetical resources, complementing the identified resources (included in the national/regional inventory). In short, the $G_{1}$ scoring will depend mostly on the quality, updated level and territory coverage of the available geological information, usually reflected in multiscale geological maps.

The $G_{2}$ criterion appraises the regional exploration information and knowledge existent on (poorly- to well-)known mining/quarrying districts, involving all kind of geological, geochemical and/or geophysical data obtained in reconnaissance or strategic and/or tactical exploration surveys. In general, this criterion reflects the exploration state-of-the-art, taking into account the available inventory of exploration works carried out in various prospects scattered in a given territory over time. In renowned mining/quarrying districts subjected to intensive (multiscale and multi-methodological) exploration surveys, the $G_{2}$ criterion should be 1.00 , implying that (1) detailed geological maps and reports, (2) in-depth geophysical data, (3) drill-hole logs, (4) representative bulk sampling and/ or (5) specific analyses/assays or other relevant technical data exist and are accessible for re-evaluation.

The $G_{3}$ criterion ponders the existent past exploitation information and knowledge, being only applicable in known mining/quarrying districts. All the information available for specific tracts (in the case, representing old mining/ quarrying sites/concessions) should be gathered and assessed as a whole, thus supporting a general appraisal of the relevance of past-exploitation activities in a given district and of their contribution to improvements on current exploration models. In renowned mining/quarrying districts subjected to intensive (continuous or intermittent) exploitation works, the $G_{3}$ criterion should be 1.00 if the compiled information proves that a thoroughly assessment of old (1) detailed geological maps and reports, (2) drill-hole logs, (3) representative bulk sampling, (4) in-depth geophysical and/or geochemical data, and/or (5) other relevant technical data can be positively done.

Finally, the $G_{4}$ criterion evaluates comprehensive, up-todate information and knowledge existent for a single specific tract. The maximum scoring of the $G_{4}$ criterion (1.00) corresponds to tracts hosting well-characterised mineral resources in terms of their fundamental attributes. This means that the assessments should rely on comprehensive and consistent data (subjected to verification and validation) obtained by means of detailed geological inspection and representative bulk sampling of outcrops, trenches, old exploitation works and/or drill-holes spaced enough to do not compromise the geological continuity of the resource and the maintenance of its physical and chemical characteristics.

Considering the goals intended for the methodological approach, the relative weight of $G_{1}, G_{2}, G_{3}$ and $G_{4}$ should be slightly different, pondering equally and heavily the criteria directly related to (regional and local) exploration data, i.e. $G_{2}$ and $G_{4}$. As illustrated in Table 1,

$$
\begin{aligned}
L G K= & {\left[\left(0.20 G_{1}\right) Q D A_{1}\right]+\left[\left(0.30 G_{2}\right) Q D A_{2}\right] } \\
& +\left[\left(0.20 G_{3}\right) Q D A_{3}\right]+\left[\left(0.30 G_{4}\right) Q D A_{4}\right]
\end{aligned}
$$

from which the following general results emerge: (1) 0.75 $<L G K \leq 1.00$, documenting very high levels of geological knowledge available for the specific tract; (2) $0.50<L G K$ $\leq 0.75$, reflecting high levels of geological knowledge available for the specific tract; (3) $0.25<L G K \leq 0.50$, indicating acceptable levels of geological knowledge available for the specific tract; and (4) $L G K \leq 0.25$, revealing insufficient levels of geological knowledge available for the specific tract.

\section{The $E c$ dimension}

The economic dimension $(E c)$ is here understood as a general measure of what is currently exploited or expectedly mined in future (its nature and relative importance), and for how long, as well as the corresponding impacts on the domestic mineral value chain and trade balance. It comprises five complementary criteria $\left(E c_{1}\right.$ to $\left.E c_{5}\right)$, each one rated into four levels, from 0.25 to 1.00 , as reported in Table 1. The appraisal of each criteria should be based on available results of independent (pre-)feasibility studies. This means that $Q D A_{j}=0$ for each $E c_{j}$ $(j=1$ to 5$)$ in specific tracts where no data are available to support a reliable economic appraisal of the identified mineral resource. In this regard, it should be emphasised that criteria behind the $E c$ dimension do not reflect directly specific qualities of the resource (such as grades, tonnages, or other) according to the reasons pointed in "Methodology" section.

The $E c_{1}$ criterion evaluates the intrinsic value of a specific tract according to natural attributes displayed by the resource. A very high (=1.00) $E c_{1}$ value denotes a strong positive appraisal made on the basis of modern feasibility studies reported in compliance with internationally recognised standards. Production of high-valuable minerals and/or products classified as critical raw materials (CRM) due to significant risks in their supply disruption should be considered as well in the assessment, contributing to a maximum $E c_{1}$ score. A high (= $0.75) E c_{1}$ value corresponds to a positive appraisal also made 
Table 1 Multi-criteria structure backing the methodology used to categorise MRoPI

\begin{tabular}{|c|c|c|c|c|}
\hline & Criterion & Score & Weight & \\
\hline \multirow[t]{16}{*}{$L G K$} & \multirow[t]{4}{*}{$G_{1}$} & 0.25 & \multirow[t]{4}{*}{0.20} & Level of geological knowledge \\
\hline & & 0.50 & & \\
\hline & & 0.75 & & $L G K=\sum^{4}\left(k_{i} G_{i}\right) Q D A_{i}$ \\
\hline & & 1.00 & & $\sum_{i=1}\left(x_{i}<\right)<x_{i}$ \\
\hline & \multirow[t]{4}{*}{$G_{2}$} & 0.25 & \multirow[t]{4}{*}{0.30} & \\
\hline & & 0.50 & & $L G K=\left[\left(0.20 G_{1}\right) Q D A_{1}\right]+\left[\left(0.30 G_{2}\right) Q D A_{2}\right]+$ \\
\hline & & 0.75 & & {$\left[\left(0.20 G_{3}\right) Q D A_{3}\right]+\left[\left(0.30 G_{4}\right) Q D A_{4}\right]$} \\
\hline & & 1.00 & & \\
\hline & \multirow[t]{4}{*}{$G_{3}$} & 0.25 & \multirow[t]{4}{*}{0.20} & \\
\hline & & 0.50 & & \\
\hline & & 0.75 & & \\
\hline & & 1.00 & & \\
\hline & \multirow{4}{*}{$G_{4}$} & 0.25 & \multirow[t]{4}{*}{0.30} & \\
\hline & & 0.50 & & \\
\hline & & 0.75 & & \\
\hline & & 1.00 & & \\
\hline \multirow[t]{20}{*}{$E c$} & \multirow[t]{4}{*}{$E c_{1}$} & 0.25 & \multirow[t]{4}{*}{0.25} & Economic dimension \\
\hline & & 0.50 & & \\
\hline & & 0.75 & & $E c=\sum^{5}\left(k_{j} E c_{j}\right) Q D A_{j}$ \\
\hline & & 1.00 & & $j=1$ \\
\hline & \multirow[t]{4}{*}{$E c_{2}$} & 0.25 & \multirow[t]{4}{*}{0.20} & \\
\hline & & 0.50 & & $E c=\left[\left(0.25 E c_{1}\right) Q D A_{1}\right]+$ \\
\hline & & 0.75 & & {$\left[\left(0.20 E c_{2}\right) Q D A_{2}\right]+\left[\left(0.20 E c_{3}\right) Q D A_{3}\right]$} \\
\hline & & 1.00 & & $+\left[\left(0.20 E c_{4}\right) Q D A_{4}\right]+\left[\left(0.15 E c_{5}\right) Q D A_{5}\right]$ \\
\hline & \multirow[t]{4}{*}{$E c_{3}$} & 0.25 & 0.20 & \\
\hline & & 0.50 & & \\
\hline & & 0.75 & & \\
\hline & & 1.00 & & \\
\hline & $E c_{4}$ & 0.25 & 0.20 & \\
\hline & & 0.50 & & \\
\hline & & 0.75 & & \\
\hline & & 1.00 & & \\
\hline & $E c_{5}$ & 0.25 & 0.15 & \\
\hline & & 0.50 & & \\
\hline & & 0.75 & & \\
\hline & & 1.00 & & \\
\hline$E v$ & $E v_{1}$ & 0.25 & 0.20 & Environmental dimension \\
\hline & & 0.50 & & \\
\hline & & 0.75 & & $E v=\sum^{7}\left(k_{l} E v_{l}\right) Q D A_{l}$ \\
\hline & & 1.00 & & $\sum_{l=1}(n l+v l) 2+1$ \\
\hline & $E v_{2}$ & 0.25 & 0.20 & \\
\hline & & 0.50 & & $E v=\left[\left(0.20 E v_{1}\right) Q D A_{1}\right]+\left[\left(0.20 E v_{2}\right) Q D A_{2}\right]$ \\
\hline & & 0.75 & & $+\left[\left(0.10 E v_{3}\right) Q D A_{3}\right]+\left[\left(0.15 E v_{4}\right) Q D A_{4}\right]$ \\
\hline & & 1.00 & & $+\left[\left(0.10 E v_{5}\right) Q D A_{5}\right]+\left[\left(0.15 E v_{6}\right) Q D A_{6}\right]$ \\
\hline & $E v_{3}$ & 0.25 & 0.10 & $+\left[\left(0.10 E v_{7}\right) Q D A_{7}\right]$ \\
\hline & & 0.50 & & \\
\hline & & 0.75 & & \\
\hline & & 1.00 & & \\
\hline & $E v_{4}$ & 0.25 & 0.15 & \\
\hline & & 0.50 & & \\
\hline & & 0.75 & & \\
\hline & & 1.00 & & \\
\hline & $E v_{5}$ & 0.25 & 0.10 & \\
\hline & & 0.50 & & \\
\hline & & 0.75 & & \\
\hline & & 1.00 & & \\
\hline & $E v_{6}$ & 0.25 & 0.15 & \\
\hline & & 0.50 & & \\
\hline & & 0.75 & & \\
\hline & & 1.00 & & \\
\hline & $E v_{7}$ & 0.25 & 0.10 & \\
\hline & & 0.50 & & \\
\hline
\end{tabular}


Table 1 (continued)

\begin{tabular}{|c|c|c|c|c|}
\hline & Criterion & Score & Weight & \\
\hline & & 0.75 & & \\
\hline & & 1.00 & & \\
\hline \multirow[t]{22}{*}{$S D A$} & $S D A_{1}$ & 0.25 & 0.20 & Social development and acceptance dimension \\
\hline & & 0.50 & & 5 \\
\hline & & 0.75 & & $S D A=\sum^{5}\left(k_{w} S D A_{w}\right) Q D A_{w}$ \\
\hline & & 1.00 & & 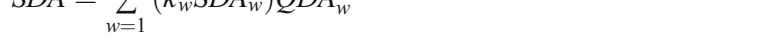 \\
\hline & $S D A_{2}$ & 0.25 & 0.15 & \\
\hline & & 0.50 & & $S D A=\left[\left(0.20 S D A_{1}\right) Q D A_{1}\right]+\left[\left(0.15 S D A_{2}\right) Q D A_{2}\right]$ \\
\hline & & 0.75 & & $+\left[\left(0.15 S D A_{3}\right) Q D A_{3}\right]+\left[\left(0.25 S D A_{4}\right) Q D A_{4}\right]$ \\
\hline & & 1.00 & & $+\left[\left(0.25 S D A_{5}\right) Q D A_{5}\right]$ \\
\hline & $\mathrm{SDA}_{3}$ & 0.25 & 0.15 & \\
\hline & & 0.50 & & \\
\hline & & 0.75 & & \\
\hline & & 1.00 & & \\
\hline & $\mathrm{SDA}_{4}$ & 0.25 & 0.25 & \\
\hline & & 0.50 & & \\
\hline & & 0.75 & & \\
\hline & & 1.00 & & \\
\hline & $S D A_{5}$ & 0.25 & 0.25 & \\
\hline & & 0.50 & & \\
\hline & & 0.75 & & \\
\hline & & 1.00 & & \\
\hline & & & & $M R R o P I_{r}=5.5 \sum_{i=1}^{4}\left(G_{i} k_{i}\right) Q D A_{i}+1.5$ \\
\hline & & & & $\left(\sum_{j=1}^{5}\left(E c_{j} k_{j}\right) Q D A_{j}+\sum_{l=1}^{7}\left(E v_{l} k_{l}\right) Q D A_{l}+\sum_{w=1}^{5}\left(S D A_{w} k_{w}\right) Q D A_{w}\right)$ \\
\hline
\end{tabular}

on the basis of modern feasibility studies reported in compliance with internationally recognised standards; production of CRM co- or by-products and/or of high-valuable mineral products are issues that should be considered in this assessment, contributing to a significant $E c_{1}$ scoring. A reasonable $(=0.50) E c_{1}$ value reflects a favourable appraisal on the basis of modern pre-feasibility studies reported in compliance with internationally recognised standards or on the basis of old positive evaluations. A minor (=0.25) $E c_{1}$ value reflects a modest or a reticent appraisal on the basis of modern prefeasibility studies reported in compliance with internationally recognised standards or on the basis of old favourable evaluations.

The $E c_{2}$ criterion intends to weigh up the mining/ quarrying lifetime active within a specific tract. The maximum scoring of $E c_{2}$ (1.00) refers to long-term (more than 40 years) exploitation works suitably designed to minimise wastes and residues and achieve an optimised production (as much as possible) of co- and by-products. A $E c_{2}$ value of 0.75 denotes a medium- to long-term (between 20 and 40 years) exploitation also committed with reduction of wastes and residues and with an optimised production of co- and by-products. Lower $E c_{2}$ values reflect medium- or short-term (less than 20 years) exploitation works not committed with both wastes/ residues reduction and/or recovery of co- or by-products ( 0.50 and 0.25 , respectively). Evident ambitious or predatory exploitation should contribute to a lower $E c_{2}$ score independently of the mining/quarrying dimension and particular industrial goals.

The $E c_{3}$ criterion aims a general appraisal of the contribution given by an active operation within a specific tract to the added-value chain of mineral product(s). It scores 1.00 if there is a strong connection with an existent domestic cluster of mineral transformation/benefiting and end-products manufacturing; 0.75 , if that relationship is moderate to acceptable; 0.50 , if the link with an existing (and growing) domestic cluster is feeble; and 0.25 , if there is no connection due to an inexistent domestic cluster of mineral transformation/ benefiting and end-products manufacturing.

The $E c_{4}$ criterion expresses the relevance of an active operation within a specific tract to the domestic market, thus contributing to the reduction of the EU's dependence in mineral imports. This general appraisal is simply scored as very high (1.00), high (0.75), moderate $(0.50)$ and trivial $(0.25)$.

The $E c_{5}$ criterion complements the previous one by measuring the significance of an active operation within a specific tract to the exports trade. The assessment scoring is analogous 
to that indicated for $E c_{4}$, classifying the significance as very high (1.00), high (0.75), moderate (0.50) and marginal (0.25).

Considering the goals intended for the methodological approach, the relative weights proposed for the five complementary criteria $\left(E c_{1}\right.$ to $\left.E c_{5}\right)$ are as follows (Table 1):

$$
\begin{aligned}
E c= & {\left[\left(0.25 E c_{1}\right) Q D A_{1}\right]+\left[\left(0.20 E c_{2}\right) Q D A_{2}\right] } \\
& +\left[\left(0.20 E c_{3}\right) Q D A_{3}\right]+\left[\left(0.20 E c_{4}\right) Q D A_{4}\right] \\
& +\left[\left(0.15 E c_{5}\right) Q D A_{5}\right]
\end{aligned}
$$

resulting for the economic dimension a general assessment that can be expressed as: (1) $0.75<E c \leq 1.00$, representing specific tracts hosting economic, world-class deposits, naturally noteworthy at international scale; (2) $0.50<E c \leq 0.75$, indicating specific tracts hosting economic deposits of national/regional significance; (3) $0.25<E c \leq 0.50$, pointing to specific tracts hosting sub-economic to marginally economic deposits, eventually significant at local scales; and (4) Ec $\leq 0.25$, specific tracts hosting non-economic deposits.

\section{The $E v$ dimension}

In the proposed methodology, the environmental dimension $(E v)$ seeks for a general measure of the impacts in natural systems related to the past, present and/or foreseen mineral extraction activities in a specific tract. It comprises seven complementary criteria $\left(E v_{1}\right.$ to $\left.E v_{7}\right)$, each one rated into four levels, from 0.25 to 1.00 (Table 1), that encompass the most relevant disturbances in the environment related to mining/quarrying, comparing them with those triggered by other land uses or economic activities, and pondering as well the efficiency/feasibility of existent or planned mitigation/ rehabilitation measures. Expectably, the judgements implicated in all criteria should be grounded by independent studies already accomplished in each specific tract where an active operation exists or is being planned, namely those commonly known as "Environmental Impact Assessments" (compulsory by law in the majority of the countries). This means that $Q D A_{l}=0$ for each $E v_{l}(l=1$ to 5$)$ in specific tracts where there is no data available to support a reliable appraisal of the environmental impacts related to past, current or foreseen exploitation of an identified mineral resource.

The $E v_{1}$ criterion considers the compatibility of mining/ quarrying operations in a specific tract with other natural values (here including biodiversity and geological heritage, already protected or not, besides unique goods and services provided by the Earth System dynamics). It will be scored as 1.00 if mining/quarrying is compatible with no specific requirements besides those inherent to a responsible exploitation activity; 0.75 , if mining/quarrying is acceptable under conditions easily achieved (accessible technology, fair costs, effortlessly implemented); 0.50 , if mining/quarrying is acceptable under highly demanding conditions, implying considerable investments and significant technical risks; and 0.25, if mining/quarrying is hardly compatible to incompatible with other natural values.

The $E v_{2}$ criterion ponders the impact of past exploitation activities in a specific tract as: 1.00 , if there is no record of past mining/quarrying activities or if their impact is negligible; 0.75 , if the impact is minor to moderate but chiefly overcame through natural attenuation processes; 0.50 , if the impact is significant but extensively minimised via well-succeeded rehabilitation programmes; and 0.25 , if the impact is significant to severe and not satisfactorily minimised or so far addressed by any rehabilitation programme.

The $E v_{3}$ criterion weighs the environmental impact of mining/quarrying in a specific tract in comparison with other (existent and projected) land uses or economic activities. This comparative assessment is scored as 1.00, if mining/quarrying has a demonstrated lower impact; 0.75 , if the impact is proved equivalent; 0.50 , if the impact is confirmed as slightly higher; and 0.25 , if it is clearly higher.

The $E v_{4}$ criterion considers the impact or the foreseen disturbances in natural flows caused by mining/quarrying activities in a specific tract, namely the effects related to soil damage/removing, acid drainage, contributions to changes in fluvial charges (dissolved and in suspension components), dust/particulate production and dispersion, gas emissions, etc. This bulk assessment classifies the impact or foreseen disturbances as low (maximum rate $=1.00)$, acceptable $(0.75)$, moderate $(0.50)$ or strong $(0.25)$.

The $E v_{5}$ criterion evaluates as a whole the ongoing or the proposed mitigation and rehabilitation measures related to mining/quarrying operations in a specific tract as: 1.00 , if the measures are effective, easily implemented and of low-cost maintenance, not requiring a systematic monitoring; 0.75 , if the measures are suitable although requiring large initial investments, despite of affordable maintenance/monitoring costs; 0.50 , if the measures are acceptable but demanding an expensive maintenance and long-lasting systematic monitoring; and 0.25 , if the measures are of dubious efficiency.

The $E v_{6}$ criterion considers the type of land use for mining and processing in a specific tract, scoring in a very simple way the occupancy (i.e. the amount of land used/disturbed) as follows: 1.00 , for underground and small-scale processing facilities; 0.75 , for underground and large-scale processing facilities; 0.50, for open-pit and small-scale processing facilities; and 0.25 , for open-pit and large-scale processing facilities. 
The $E v_{7}$ criterion assesses the responsibility with the search and implementation of adequate measures to buffer the mining wastes/residues produced by an active operation within a specific tract. The maximum scoring of $E v_{7}$ (1.00) denotes the existence of small amounts of wastes/residues duly accumulated and buffered, while the minimum scoring (0.25) reflects the presence of large amounts of wastes/residues questioningly accumulated and buffered. In-between values of $E v_{7}$ represent acceptable $(0.75)$ or significant $(0.50)$ amounts of wastes/residues correctly or tolerably accumulated and buffered, respectively.

Assembling all the criteria $\left(E v_{1}\right.$ to $\left.E v_{7}\right)$ and weighing differently each one according to the goals intended for the methodological approach, the resulting equation to evaluate the environmental dimension in a given specific tract is (Table 1):

$$
\begin{aligned}
E v= & {\left[\left(0.20 E v_{1}\right) Q D A_{1}\right]+\left[\left(0.20 E v_{2}\right) Q D A_{2}\right] } \\
& +\left[\left(0.10 E v_{3}\right) Q D A_{3}\right]+\left[\left(0.15 E v_{4}\right) Q D A_{4}\right] \\
& +\left[\left(0.10 E v_{5}\right) Q D A_{5}\right]+\left[\left(0.15 E v_{6}\right) Q D A_{6}\right] \\
& +\left[\left(0.10 E v_{7}\right) Q D A_{7}\right]
\end{aligned}
$$

Therefore, if (1) $0.75<E v \leq 1.00$, there is evidence for a low environmental impact and a strong compatibility between natural values and mining/quarrying in that specific tract; (2) $0.50<E v \leq 0.75$, the environmental impact (solved with some correction measures) and compatibility between natural values and mining/quarrying in that specific tract are acceptable; (3) $0.25<E v \leq 0.50$, the environmental impact (mitigated with significant correction measures) is moderate and the compatibility between natural values and mining/quarrying in that specific tract is tricky; and (4) $E v \leq 0.25$, the environmental impact is considerable (not mitigated suitably making use of known, or proposed, technologies/methods) and the compatibility between natural values and mining/quarrying in that specific tract is problematic.

\section{The $S D A$ dimension}

The social development and acceptance dimension $(S D A)$ comprises five complementary criteria $\left(S D A_{1}\right.$ to $S D A_{5}$ ), each one rated into four levels, from 0.25 to 1.00 (Table 1). The intention is double: (1) to weigh the communal development triggered by mining/ quarrying operations in a specific tract, including their comparative impact in relation to other (traditional and non-traditional) economic sectors; and (2) to evaluate the community awareness and acquiescence in relation to mining/quarrying operations in a specific tract, as well as the compatibility between these industrial activities with other land uses by society. Once more it is expected that the judgements implicated in all criteria involved in SDA dimension are supported by independent studies already accomplished in each specific tract where an active operation exists or is being planned. Regularly, these independent studies are not conducted, but a strong recommendation in this matter should be done. In these circumstances, the starting point for the $S D A$ assessment is at best semiquantitative or even qualitative. Whenever impossible to reasonably justify a numerical estimation for each $S D A_{w}(w=1$ to 5$), Q D A_{w}=0$, preventing any attempt to appreciate (even roughly) the $S D A$ dimension related to ongoing or foreseen mineral exploitation in a given specific tract.

The $S D A_{1}$ criterion assesses the public acceptance in relation to mining/quarrying operations in a specific tract as strong (1.00), moderate $(0.75)$, sceptic to apprehensive (0.50) and doubtfulness to opposition (0.25). The $S D A_{2}$ criterion evaluates the compatibility of mining/quarrying operations in a specific tract with other land uses by the community as strong (1.00), good $(0.75)$, acceptable $(0.50)$ and hardly compatible $(0.25)$. The $\mathrm{SDA}_{3}$ criterion measures the impact in the population settlement and growth caused by mining/quarrying operations in a specific tract as outstanding (1.00), considerable $(0.75)$, moderate $(0.50)$ and inconsequential (0.25). The $S D A_{4}$ criterion considers the impact in direct/indirect jobs creation a welfare rise produced by mining/quarrying operations in a specific tract as noteworthy (1.00), large $(0.75)$, moderate $(0.50)$ and trivial (0.25). Finally, the $S D A_{5}$ criterion balances the wealth improvement associated with the mining/quarrying activity in a specific tract (including taxes and royalties) with other complementary economic sectors, being scored as remarkable/impacting national GDP (1.00), significant at regional scale $(0.75)$, enough to stimulate local development (0.50), and with just marginal impacts $(0.25)$.

The overall SDA dimension is obtained by considering different weights for the criteria $\left(S D A_{1}\right.$ to $\left.S D A_{5}\right)$ according to the goals intended for the approach, as follows (Table 1):

$$
\begin{aligned}
S D A= & {\left[\left(0.20 S D A_{1}\right) Q D A_{1}\right]+\left[\left(0.15 S D A_{2}\right) Q D A_{2}\right] } \\
& +\left[\left(0.15 S D A_{3}\right) Q D A_{3}\right]+\left[\left(0.25 S D A_{4}\right) Q D A_{4}\right] \\
& +\left[\left(0.25 S D A_{5}\right) Q D A_{5}\right]
\end{aligned}
$$

expressing (1) a remarkable short- to long-term social development and strong public acceptance, if $0.75<S D A$ $\leq 1.00$; (2) a significant short- to medium-term social development and moderate public acceptance, if $0.50<S D A$ $\leq 0.75$; (3) a moderate short- to medium-term social 
development and acceptable levels of social distrust, if 0.25 $<S D A \leq 0.50$; and (4) an irrelevant social development complemented by a strong public suspicion, if $S D A \leq 0.25$.

\section{Final MRoPI categorization}

Updating the equation (3) by replacing each parameter with the respective set of criteria presented in sections from "The $L G K$ dimension" to "The SDA dimension", results (Table 1):

$$
M R o P I_{r}=5.5 \sum_{i=1}^{4}\left(G_{i} k_{i}\right) Q D A_{i}+1.5\left(\sum_{j=1}^{5}\left(E c_{j} k_{j}\right) Q D A_{j}+\sum_{l=1}^{7}\left(E v_{l} k_{l}\right) Q D A_{l}+\sum_{w=1}^{5}\left(S D A_{w} k_{w}\right) Q D A_{w}\right)
$$

Accordingly, the MRoPI categorisation, depending on the $M R o P I_{r}$ value, will be necessarily scattered in the $[1,10]$ range as imposed by the scaling normalising factor. This means that all possible scenarios will be constrained between the lowermost score $\left(M R o P I_{r} \approx 1\right)$, representing the lack of enough geological knowledge to support the delimitation of any specific tract, and the highest score $\left(M R o P I_{r} \approx 10\right)$, ideally characterising specific tracts that host active and wellsucceeded exploitations with low environmental impacts, contributing to high levels of social development and deserving also strong public acceptance. In this regard, it should be emphasised that the proposed methodology aims simply a categorization of specific tracts hosting mineral resources, whose access and use must be safeguarded. Therefore, the available geological knowledge at a given time is the decisive factor, allowing by itself an evaluation of all kinds of potential specific tracts. Complementary appraisals regarding the remaining dimensions (economic, environmental and social development and acceptance) should focus only in those tracts that enclose active mining/quarrying operations or promising prospects for which the compulsory environmental impact assessments, (pre-)feasibility studies and feedbacks on the public acquiescence already exist. In other words, the indicated methodology to estimate $M R o P I_{r}$ does not represent a tool to perform a comprehensive survey on the economic potential and the environmental impact related to active or foreseen mining/quarrying works in a certain specific tract, neither stands for a way to investigate the social development and acceptance of these industrial activities. Instead, it uses the available information disclosed by independent studies, handling conveniently the data to ensure acceptable levels of harmonisation and further fulfilment of the aforementioned criteria in each complementary dimension.

\section{Defining the MRoPI $r$ threshold value and related implications}

As referred in previous sections, $L G K$ is the decisive dimension sustaining $M R o P I_{r}$ estimations whatever the specific tract hosting promising or identified resources. $L G K$ is also a regionalised variable and the logic behind criteria $G_{1}$ to $G_{4}$ reflects also this important feature. Therefore, and because $E c$, $E v$ and $S D A$ dimensions can only be suitable evaluated in specific tracts where active mining/quarrying operations or promising prospects already exist, the threshold value definition must rely exclusively on $L G K$, which is also consistent with the reasoning presented in "Mineral resources of public interest and/or public importance" and "Reasoning behind the MRoPI classification and mapping" sections. Different combinations of $G_{1}$ to $G_{4}$ criteria show that high levels of geological knowledge available for a specific tract (i.e. $L G K \approx 0.73$ ) offer the confidence needed to decide about the threshold value. If so, the latter boundary should be placed at $M R O P I_{r}=4$. Furthermore, if the meanings of criteria $G_{1}$ to $G_{4}$ are considered, a rough correspondence between different $M R O P I_{r}$ values and the classes previewed in the "McKelvey diagram" through the "geological confidence" axis (e.g. US Geological Survey, 1980) can be done, as illustrated in Fig. 1; in such approach, all the $M D o P I_{r}$ scores below 2 or above 9 are undistinguishable. To be highlighted also is the correspondence between "inferred resources" and $M R O P I_{r}$ scores somewhat above 5 till 6 . This can be taken as equivalent to a threshold for a Reserve Base estimation, in the sense of USGS (2009). Indeed, the Reserve Base estimates provide a lower limit to the extractable resource; i.e. (...)" that part of an identified resource that meets specific minimum physical and chemical criteria related to current mining and production practices, including those for grade, quality, thickness and depth".(...) Note that this definition is not significantly tied to the economics of extraction.

\section{Mapping $M R o P I_{r}$}

Once classified with a $M R O P I_{r}$ score, all the specific tracts can be plotted in a map by considering each area or its central point. Both plotting options have advantages and disadvantages. Using the "area option", the resultant map will show a collection of independent/unrelated polygons that can be marked differently (by means of distinct colours or other infilling signs) according to their $M R o P I_{r}$ scores; intending a common map for distinct mineral commodities, an explicit 
Mining/Quarrying District

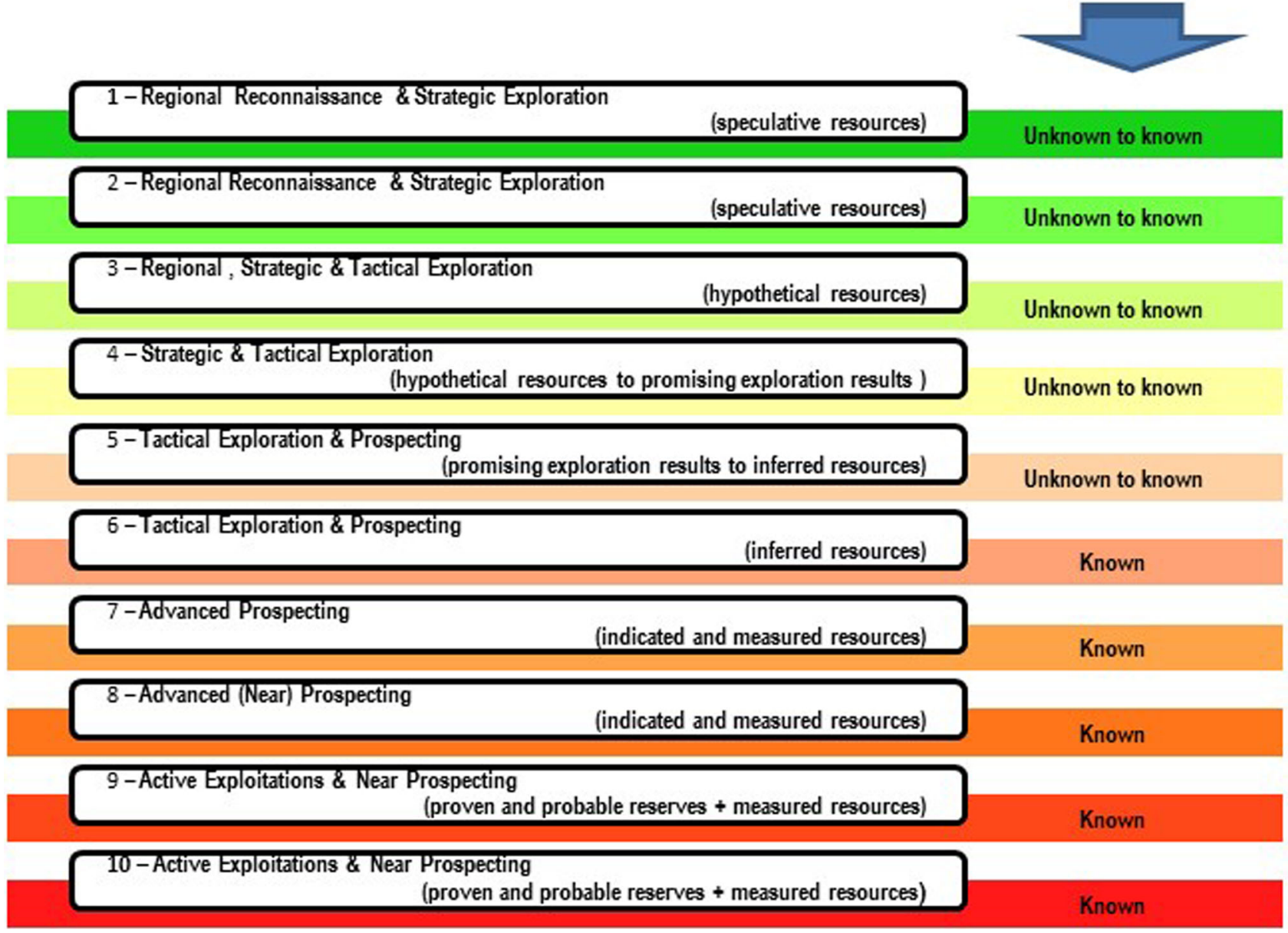

Fig. 1 Schematic illustration of the $M R o P I_{r}$ value distribution in the $[1,10]$ range and conceivable correspondence with the classes of resources previewed by the "McKelvey diagram" through the "geological confidence" axis

label should be added to each polygon. By means of the "central point" option, a schematic bubble map representation can be used with distinct diameters denoting different $M R o P I_{r}$ classes and choosing different colours to figure up distinct mineral commodities, always using coherent geological criteria. However, in presence of a significant spatial density of point data a contour map can be tentatively built on the basis of the distribution of specific tracts categorised in the $4 \leq M R o P I_{r} \leq 10$ range, thus evidencing the foremost tract clusters that can be purposed to be safeguarded per mineral commodity or per a group of mineral commodities.

\section{Interpolation models}

In geosciences, the interpolation intends to address the common problem of characterising a certain phenomenon with a restrict number of samples, each one linked to a given spatial location. Interpolation techniques can be systematised in two major groups: deterministic and stochastic; both approaches are based on the similarity of nearby point data. Deterministic techniques use mathematical functions for interpolation whereas stochastic approaches use both mathematical and statistical methods to create surfaces and assess the uncertainty involved in predictions (e.g. Lam, 1983; Burrough, 1986; Declercq, 1996; Soares, 2000). Common geostatistical (interpolation) methods are based on the Theory of Regionalised Variables which considers both the structured and random features of spatially distributed variables, providing quantitative tools for their description and optimal unbiased estimation. The regionalised variables $R V$ are thus considered as insights of a random function and, consequently, all the observations must have the same probability distribution; this is intrinsically related to the spatial homogeneity of the phenomenon and is referred as stationarity. In common approaches, the restrictive second order stationarity hypothesis (of mean and variance), or the less restrict intrinsic hypothesis (just between the sample pairs), is imposed.

The spatial continuity and variability of $R V$ are modelled by the variogram that describes the spatial auto-correlation of a certain phenomenon as function of the distance and direction of sample pairs. Geostatistical methods of spatial estimation of regionalised phenomenon are known as kriging and are based 
on the structural model validated by the variogram and sample information. Kriging aims the best possible linear estimator by a linear combination of sample values and weights, whose calculation is based on the variogram and on two fundamental criteria: the non-bias condition and the minimum variance of estimation (details on the mathematic formalism and theory of kriging can be found in, e.g., Matheron, 1962-63, 1971; David, 1977, Davis, 1986; Sousa and Muge, 1990; Goovaerts, 1997; Soares, 2000). The kriging family interpolators can be addressed by means of several techniques, being the ordinary kriging the most commonly used; simple kriging is similar to the ordinary procedure, but only the mean or the tendency of the regionalised phenomenon is considered stationary and known.

For the $M R o P I_{r}$ mapping, simple kriging was used to model the variable within the spatial domain, i.e. the Portugal mainland. However, the structural modelling of the variogram was mainly focused on the variability at local/regional scale so that areas with $M R o P I_{r} \geq 4$ could be delimited, looking down on the lower values representing tracts with less significant $L G K$ values. To reinforce the physical support and improve the structural modelling, the vertices of areas granted for mineral exploration were also used, by producing more data points and improving the error of prediction of the safeguarding areas. In brief, the interpolation areas were developed within the kriging formalism and evaluated by an empirical approach, guiding to slightly changings/ readjustments in the modelling process until achieving the final map. In certain cases, simple kriging with local moving average could improve the characterisation of local variation, if the variable of concern is related to very distinct geological areas. Alternatively, kriging with external drift (KED) could represent a more accurate method approaching if detailed geological information is available, once it allows the modelling of the spatial structure and anisotropy in function of the geological groups where these structures are included.

\section{"Base metals" resources in Portugal: an example of application}

Following to the usual definition, all metals that oxidise, tarnish or corrode relatively easily when exposed to air or moisture can be classified as "base metals". These include various chemical elements forming many ore types that played an increasingly role throughout the history of Human civilization, becoming invaluable to the global economy because of their utility and ubiquity. Current (static) criticality studies show that none of the "base metals" display worrying supply risks, many of them recording inclusively quite favourable and rising recycling rates; so, why should we care about safeguarding the future access to primary resources of "base metals"? After the metals boom from ca. 2003 to 2008 and the subsequent negative shocks hitting the world's economy triggered by delayed cascade-effects rooted in the 2008/09 financial crisis, a strong reversion of commodity prices took place along with a generalised decrease in consumption (e.g. Humphreys, 2010; Veld et al., 2011). This record has been sustaining sceptical views on the need of keep investments in mineral exploration and in launching new mining projects. However, this period of slower growth in the traditional consuming countries and obvious deceleration of emerging economies will have an end, and the demand for minerals remains as currently is or will grow again (e.g. Arndt et al., 2017). It is not possible to ascertain when this turning point will definitely happen, but it is well-known that major breakthroughs in economic cycles and markets are often more ruled by unpredictable financial and geopolitical events. In addition, if sustainability is the main desideratum, evident paths towards consolidated rates of global economic growth should occur in (a near) future and this will have significant impact on minerals demand, ultimately driving the industry performance, as clearly showed by the history of economics. Therefore, even in presence of improved recycling rates, the future access to demonstrated or inferred resources of "base metals" should be safeguarded and persistence in (innovative, cutting-edge) exploration surveys should be encouraged.

In the present example, only copper, zinc and lead were included in the general label "base metals". This represents just an operational convenience, allowing a straight use of the Information System of Portuguese Mineral Occurrences and Resources (SIORMINP; Filipe, 2010) where large part of the information needed to test the MRoPI methodology was obtained. According to official reports (Filipe et al., 2010), the total $\mathrm{Cu}$, $\mathrm{Zn}$ and $\mathrm{Pb}$ metal reserves in Portugal, were estimated at ca. 1.4 Mt., 5.5 Mt. and 1.3 Mt., respectively, on the basis of data available till 2009. The country is indeed one of the EU's leading producers of $\mathrm{Cu}$ together with other mineral products and most of its "base metals" reserves cluster at the South Portuguese Zone (SPZ) within the Portuguese segment of the so-called Iberian Pyrite Belt of Palaeozoic age (e.g. Inverno et al., 2015, and references therein). In this world-class polymetallic massive sulphide metallogenic belt, two main underground active mines (Neves Corvo and Aljustrel) are complemented by several other demonstrated resources partly (Lousal) or incipiently (Caveira) developed or never exploited (Lagoa Salgada, Salgadinho), besides some promising prospects (e.g. Sesmarias). Additional resources of "base metals" in Portugal are located to the north, in the Ossa Morena Zone (OMZ), comprising different ore types distributed in various belts of prevalent Palaeozoic age, being worth noting the never exploited orebodies of Algares, Portel and Enfermarias, as well as the poorly worked Preguiça-Vila Ruiva sulphide accumulations (e.g. Tornos et al., 2004; Mateus et al., 2013, and references therein). Further north, in the Central Iberian Zone (CIZ), a significant number of occurrences of "base metals" and lode-type resources of minor dimension generated in 
Late Variscan or Eo-Alpine times (some of them subjected to intermittent, shallow-underground mining works in the past) are also recognised by the national catalogue, but significant exploration investments are needed to confidently discard their possible future interest (e.g. Mateus and Noronha, 2010, and references therein). The same happens with the scarce occurrences of "base metals" so far identified within sedimentary sequences forming the Mesozoic-Cenozoic basins (MCB) occupying the western- and southernmost borders of Portugal mainland (Lusitanian and Algarve Basins, respectively).

The yearly production of concentrates of "base metals" in Portugal increased significantly since 1989, when the Neves Corvo mine started in definitive its activity, and is largely dominated by Cu-concentrates (Fig. 2a). Together, and since 1990, the concentrates of "base metals" represented the leading fraction (usually above $90 \%$ ) of the whole domestic production of metallic ore concentrates that also included W- and Sn-bearing phases (wolframite and cassiterite, respectively) as prime substances (Fig. 2a). In the same time frame, the concentrates of "base metals" constituted a small part (from ca. 0.3 to $1 \%$ ) of the total amount of mineral products generated in Portugal, but

a
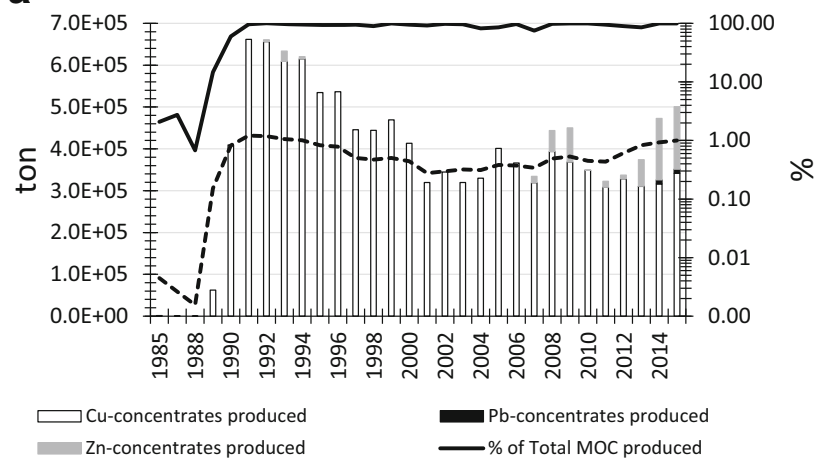

- - $\%$ of Total Mineral Products Produced

b

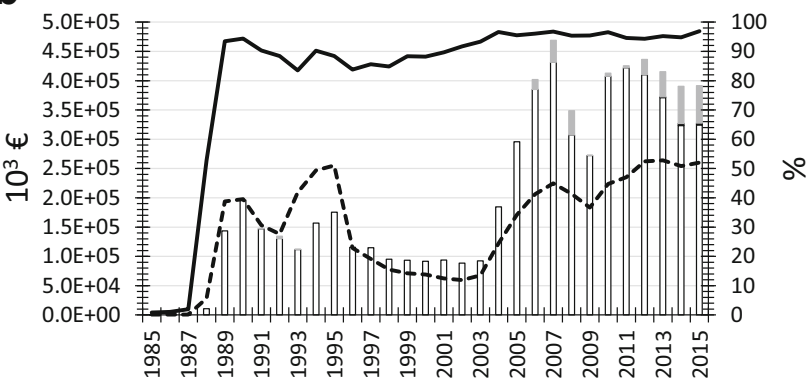

$\square$ Cu-concentrates produced $\square$ Pb-concentrates produced

- $\%$ of Total Mineral Products Production

Fig. 2 Production of $\mathrm{Cu}-, \mathrm{Pb}$ - and $\mathrm{Zn}$-concentrates in Portugal (a) and respective revenues (b) during the 1985-2015 period. In both plots, the secondary vertical axis informs on the relative proportion of these concentrates in the total amount of mineral products and metallic ore concentrates (MOC) produced and their returns. The data used were obtained in the official website of the Portuguese Mining Authority their recorded economic value was remarkable, representing ca. 20 to $50 \%$ of the annual revenue from mineral production, excluding the 1997-2003 interval when those figures decreased notably and reached lows of ca. $12 \%$ in 2002 ; even so, for the 1997-2003 period, the returns related to the production of concentrates of "base metals" ranged between ca. 84 and ca. $92 \%$ of the amounts collected from the whole domestic production of metallic ore concentrates (Fig. 2b). The exports of concentrates of "base metals" recorded also a positive, although irregular, evolution, representing always a significant part (clearly, dominant in some periods) of the total of metallic ore concentrates exported, and a noteworthy share of the incomes related to the international trade of all the Portuguese mineral products (Fig. $3 \mathrm{a}, \mathrm{b}$ ); in the last 30 years, the imports of "base metals" were minor and quite irregular.

Considering the 1996-2015 period, for which an adequate official disaggregation exists for the incomes from produced, exported and imported goods of different nature, it is clear that the overall trade evolution recorded by mineral products in general (Fig. 4a), and concentrates of "base metals" in particular, is positive. Indeed, in relation to the annual gross

a

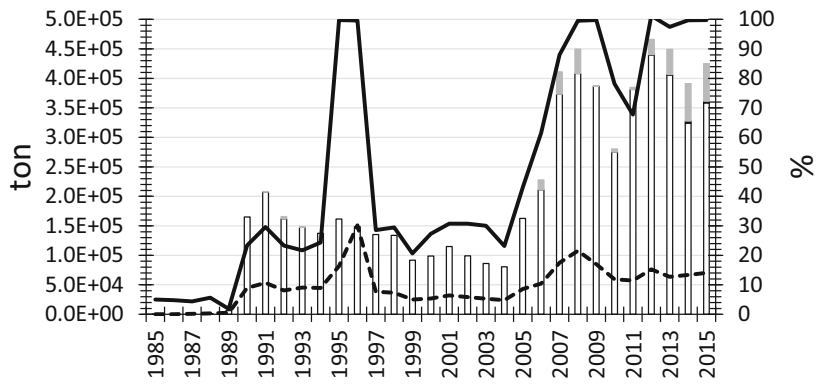

$\square \mathrm{Cu}$-concentrates exported $\square$ Pb-concentrates exported

Zn-concentrates exported $\quad$ - of Total MOC exported

- - \% of Total Mineral Products Exported

b

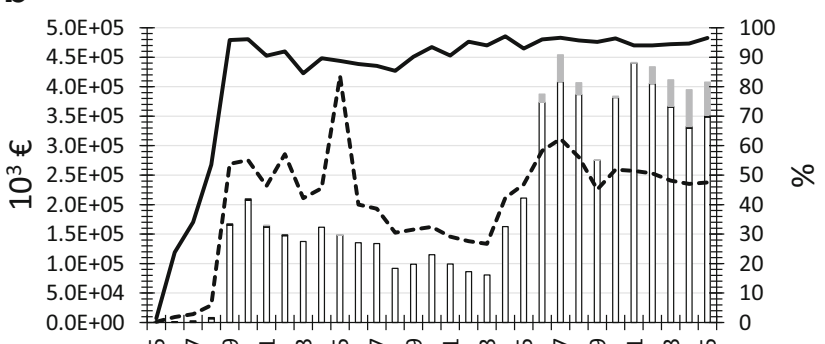

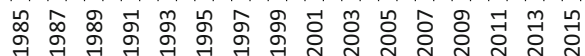

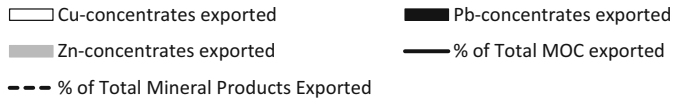

Fig. 3 Exports of $\mathrm{Cu}$-, $\mathrm{Pb}$ - and $\mathrm{Zn}$-concentrates in Portugal (a) and respective returns (b) during the 1985-2015 period. In both plots, the secondary vertical axis informs on the relative proportion of these concentrates in the total amount of mineral products and metallic ore concentrates (MOC) exported and their incomes. The data used were obtained in the official website of the Portuguese Mining Authority 
domestic production (GDP, Fig. 4b): (1) the revenues obtained with all the exported goods evolved from 18 to $27 \%$ of GDP, not balancing suitably the values spent with imports, which recorded a variation from 28 to $35 \%$ of GDP; (2) the total production of mineral products in Portugal has remained around $0.4-0.5 \%$ of GDP, and their imports decreased from ca. 0.28 to $0.24 \%$ of GDP, while exports grew from ca. 0.34 to $0.48 \%$ of GDP; and (3) the production of concentrates of "base metals" raised from 0.12 to $0.24 \%$ of GDP, coupled by an increasing amount collected from exports $(0.14$ to $0.24 \%$ of GDP), considerably above the values expended with imports (up to $0.026 \%$ of GDP).

\section{Criteria densification}

According to the SIORMINP national catalogue, the number of entries documenting the known occurrences and resources of

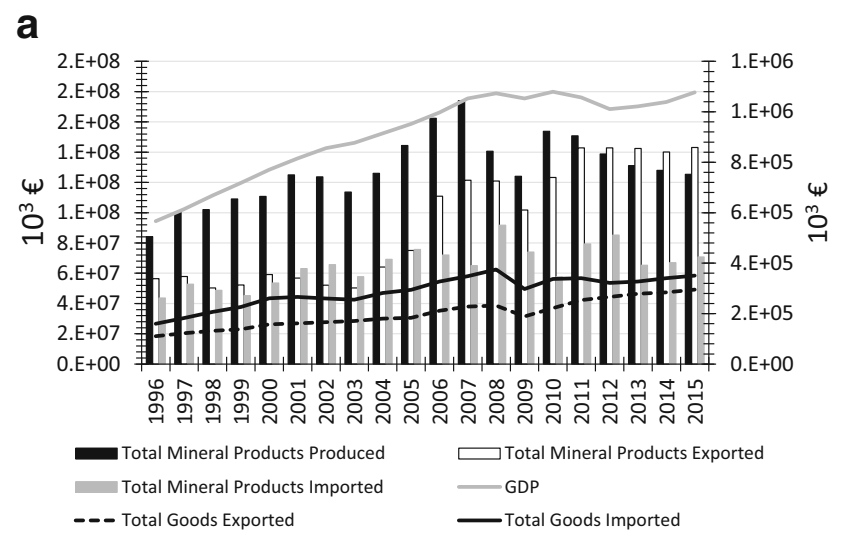

b

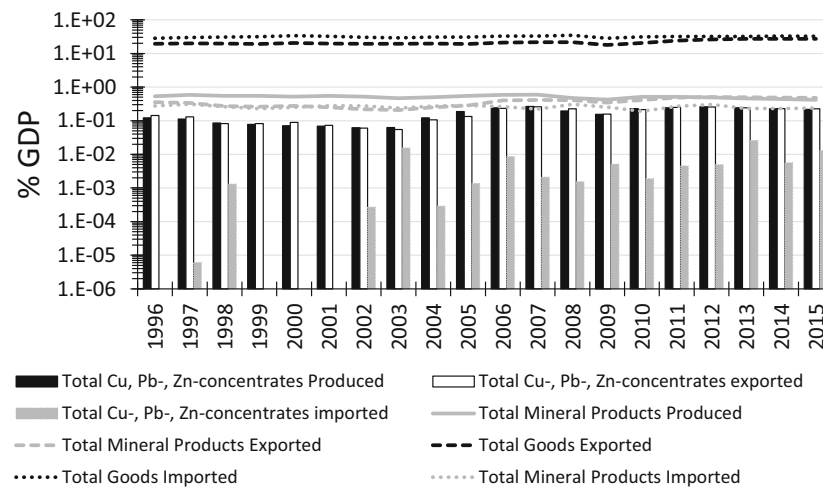

Fig. 4 a Annual evolution of the Portuguese GDP from 1996 to 2015 compared with the incomes or the spent amounts recorded, respectively, by the total of exported or imported goods (primary vertical axis). The total of mineral products produced in Portugal during the same time series is also shown along with the revenues of their exports and the values spent with their imports (secondary vertical axis). b Annual production/ exports/imports in \% GDP allowing comparing the relative weight of "base metals" concentrates, total mineral products and total of goods in the Portuguese trade balance from 1996 to 2015. The data used were obtained in the official websites of the Portuguese Mining Authority and of the National Institute of Statistics "base metals" in Portugal is 241. These specific tracts are irregularly scattered all over the Portuguese mainland whose geological background is adequately characterised and mapped, thus justifying the $G_{1}$ criterion score of 1.00 . The existing regional exploration data and knowledge for "base metals" is remarkable for SPZ (although mostly focused in the Iberian Pyrite Belt), but not so noteworthy for OMZ, getting poorer for $\mathrm{CIZ}$ and $\mathrm{MCB}$, strongly suggesting that a different $G_{2}$ scoring should be used. In the present approach $G_{2}$ values of $1.00,0.75$ and 0.50 were assigned to each specific tract according to its location in SPZ, $\mathrm{OMZ}$ and CIZ/MCB, respectively, after confirm that it is irrelevant for final results differentiate in this criterion specific tracts placed at CIZ or MCB. Similarly, there are obvious discrepancies for the available record on past exploitation information in function of the intensity and continuity of mining works performed in the specific tracts listed in the catalogue, strengthening the differentiation already put in evidence for $G_{2}$ criterion. Consequently, a general appraisal of the relevance of past-exploitation "base metals" in SPZ, OMZ and CIZ/MCB, and of their contribution to improvements on current exploration models, was scored as $0.75,0.50$ and 0.25 , respectively, which reflects a conservative estimation; again, using of same score for specific tracts in CIZ and MCB does not have impact in the final results. Finally, the assessment of $G_{4}$ criterion for each specific tract involved a combined set of sub-criteria (Fig. 5), as follows: (1) a base score ranging from 0.15 to 1.00 was assigned according to the resource's category reported in the official catalogue (which follows the 1997 version of the United Nations International Framework Classification for Reserves/Resources); (2) the base score was risen one level when in presence of medium- to largesized deposits, also indicated in the inventory as having "high potential" by the most recent official appraisal (Filipe et al., 2010); (3) the result obtained after application of the previous two criteria was corrected by lowering one or two score levels if "base metals" are the second or third prime substance, respectively, forming the resource; and (4) a final fine-tuning was considered to discriminate, in terms of geological knowledge, the most frequent and lowest category ("mineral"), by adding or subtracting 0.1 to the score achieved in function of bonus or penalty sub-criteria, respectively, reflecting the existence of added-value information about the specific tract gathered through exploration and exploitation works carried out in that particular site. Following this criteria densification, the $L G K$ dimension of each 241 specific tracts was estimated.

The $E c, E v$ and $S D A$ dimensions were only examined for the active mines of Neves Corvo and Aljustrel. The $E c_{1}$ criterion complements the information indicated by $G_{4}$ (from $L G K$ ), having Neves Corvo the maximum score, considering the well-grounded estimations of proved reserves, as reported in the National Instrument 43-101 and regularly disclosed by the Company official bulletins. For Aljustrel, only estimations of probable reserves are known, thus justifying a scoring of 0.75 . With respect to the mine lifetime evaluated by $E c_{2}$, both 
1. Scoring SIORMINP's category according to the 1997 version of the United Nations International Framework Classification for Reserves/Resources

2. Rising one level of the base score produced by criterion 1 . when in presence of medium- to large-sized deposits indicated as having "high potential" by the most recent official appraisal (Filipe et al., 2010).

3. Lowering one or two score levels if $\mathrm{Cu}, \mathrm{Zn}$ or $\mathrm{Pb}$ are the second or third prime substance, respectively, forming the resource.

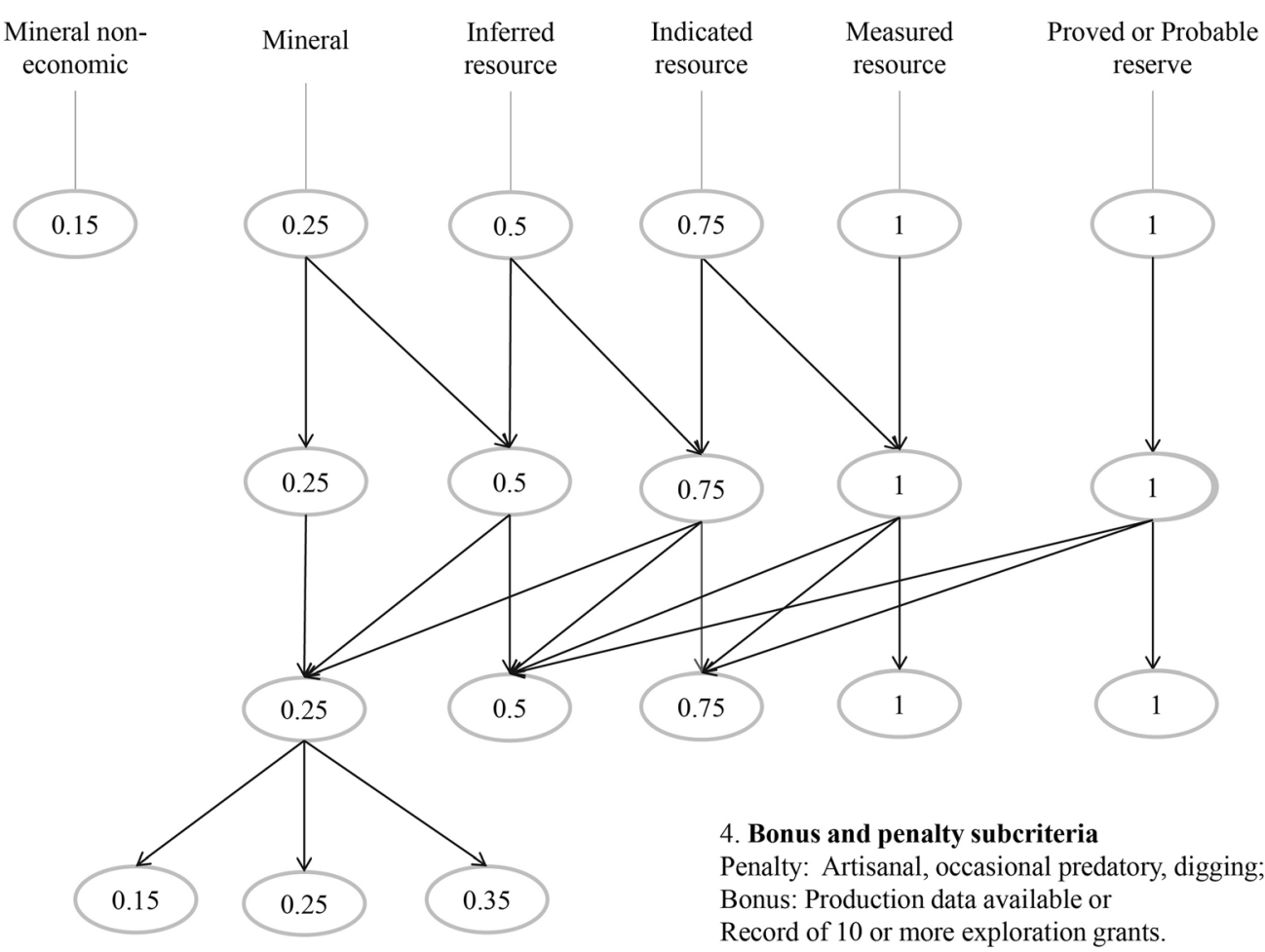

Fig. 5 Illustration scheme showing the sub-criteria used, and correspondent score, to assess $G_{4}$ for each specific tract

mines, although having a quite distinct track record, were scored with 1.00. Since there is no domestic cluster for transformation/benefiting nor end-product manufacturing for metallic ores in Portugal, both mines were classified with the minimum $E c_{3}$ score. In fact, all the produced concentrates from Neves Corvo and Aljustrel are exported/sold to smelters primarily European based, highly contributing to the domestic European market, therefore justifying for both mines the maximum scoring of $E c_{4}$. Nevertheless, the impact on the exports trade is moderate for Neves Corvo and marginal for Aljustrel; consequently, $E c_{5}$ was scored as 0.50 and 0.25 , respectively.

Considering now $E v_{1}$, Neves Corvo stands out as an (internationally recognised) example of good practice and responsible mining (having an Environmental Management System that follows ISO 14001 Standard, besides promoting biodiversity in the mine area through the development of various projects), scoring the maximum value. Aljustrel scores 0.75 , attending to the fulfilment of all the requirements imposed by the mandatory environmental licence and to the promotion of several complementary studies developed under the scope of EIA. In what concerns $E v_{2}$ criterion, Neves Corvo scores again the maximum because there is no historical mining in that specific tract. Aljustrel, by the contrary, has a long mining history with a significant impact inheritance which has being minimised through a series of recent and wellsucceed rehabilitation programs; taking into account the effects already produced by several correction measures, the ascribed score was 0.50 . No attempts were made to quantify $E v_{3}$ given the inexistence of reliable data to do so. A $E v_{4}$ score of 0.75 was ascribed to both mines since active measures to minimise impacts resulting from ores exploitation and subsequent treatment/beneficiation exist and are monitored, thus demonstrating acceptable levels of disturbance in natural flows. Regarding $E v_{5}$, Neves Corvo was scored with the maximum value, considering all the environmental evaluations and monitoring covered by the Environmental Management System; Aljustrel was scored at a lower level (0.50) given the influence of its inheritance which still demands an expensive maintenance and long-lasting systematic monitoring. As they are both extensive underground mines with relatively large-scale processing facilities, their $E v_{6}$ score was settled at 0.50 . The $E v_{7}$ score ascribed for both mines was also the same (0.75), reflecting the production of acceptable amounts of mining wastes/residues (in comparison with the exploited volumes) further duly accumulated and buffered.

There is no any formal study on the social acceptance of mining activities performed at Aljustrel and Neves Corvo; therefore, $S D A_{1}$ cannot be properly assessed, notwithstanding the positive indicators gathered in informal surveys to the communities. The compatibility with other land uses scores 1.00 for both mines, according to the information displayed by the recently updated Municipal Land-Use Plans. Maximum scores were also assigned to $S D A_{3}$ and $S D A_{4}$ criteria, taking into account the available social and economic figures; indeed, both 
mines are the main employers of the entire Alentejo region, influencing decisively the population settlement and growth, as well as the creation of several thousands of direct and indirect jobs. According to the National Economic Statistics, the Neves Corvo outputs have impact in the national GPD, thus placing the $S D A_{5}$ at 1.00; the influence of Aljustrel production is lower, but even so significant at a regional scale, justifying a $S D A_{5}$ of 0.75. As a result, the final $M R o P I_{r}$ for Neves Corvo and Aljustrel is 8.73 and 8.19 , respectively.

The areas granted for mineral exploration were used to densify the original scattered map formed by the 241 specific tracts, by integrating the vertices and centroids from the correspondent polygons, giving physical support and improving the interpolation process. Starting from 2007 until April of 2016, 588 granted areas related to $\mathrm{Cu}, \mathrm{Zn}$ or $\mathrm{Pb}$ exploration were selected. These areas correspond to all the exploration polygons assigned to one or more companies during that time span, resulting in superimposed (dis)similar polygons for the same area. Instead of editing these polygons to address the overlapping problem and take the external contour, all the interesting polygons were preserved and duplicated points (vertices and centroids) afterwards removed. The emerging point spatial pattern is densified in areas of higher interest where there are more knowledge resulting from exploration activities, providing a solid physical support for modelling.

The procedure started with the classification of polygons in terms of ranking position regarding $\mathrm{Cu}, \mathrm{Zn}$ or $\mathrm{Pb}$, according to the list of substances presented in the attributes of the granted areas. The final ranking score corresponds to the highest position from two sequential positions of at least two metal substances. Once the classification of the polygons was completed, the final subset group was selected according two main conditions: (1) contain at least one specific tract; or (2) display a classification within the first three ranking positions. As a result of this procedure, 203 polygons of the initial 588 were selected and the subsequent conversion into centroids and vertices (followed by removal of duplicate points) originated a total of 5116 new data points. The assignment of $M R o P I_{r}$ values to the vertices and centroids was done using the spatial join with the 241 specific tracts by selecting the closest operation (Euclidean distance). A final and punctual tuning was made to reinforce the role of the most external vertices (located in the external contour) classified as $M R o P I_{r} \geq 4$ as physical barriers, by lowering them to the level immediately below (3.9875) in order to contain as much as possible the interpolation process within the selected granted areas.

\section{Results}

The results herein present were produced in ArcGIS 10.4.1 and the Geostatistical Analyst tool was used in all the statistical data handling; all data information is referenced to PT-
TM06/ETRS89 - European Terrestrial Reference System 1989. Figure 6 illustrates the general task flow scheme, showing three major compartments implicated in distinct work environments. The first one refers to the MRoPI classification of mineral resources and represents the work presented in the previous section related to $L G K, E c, E v$ and $S D A$ subcriteria densification and application. The subsequent tasks were based on the obtained $\mathrm{MRoPI}_{r}$ results and were mostly produced in GIS and Geostatistic environment.

Figure 7 shows the spatial distribution of the 241 "base metals" specific tracts categorised according to their $M R o P I_{r}$ value in two classes (above and below the threshold 4), and symbolised in terms of substances. One may therefore conclude that, in Portugal mainland, there are 25 specific tracts with $M R o P I_{r} \geq 4$ located in SPZ and OMZ. In Fig. 8, the spatial distribution of the external contour of areas granted since 2007 for "base metals" exploration works is shown, according to the official information disclosed by the Portuguese Mining Authority, as well as the resulting 5116 data points obtained as previously described. These points are predominantly located in the south of Portugal, although there are a few in the North with minor importance according to the current geological knowledge. These 5116 data points together with the 241 specific tracts were used to define interpolation areas linked to resources of "base metals".

Simple kriging was the selected interpolation method to generate the corresponding surfaces. This was preceded by a simple exploratory spatial data analysis to better describe the spatial arrangement and spread characteristics of the variable, assisting afterwards the design of variography parameters. Basic statistics information and histograms can be found in Fig. 9 showing that the distribution based on 5357 data points displays less dispersion in the higher values, being also less asymmetric than the distribution generated by the 241 specific tracts; both distributions show positive asymmetry. The differences found reflect mainly the increasing of higher data values, quite evident in the third quartile value, spatially located in the South of Portugal; the spatial distribution of both data in Fig. 10 illustrates clearly the general tendency revealed by the highest values in the South, decreasing to the North. Considering the spatial arrangement of data point, particularly those with higher values, it seems clear the development of an anisotropy coincident with the main Variscan structural directions, quite distinct at South, characterised by a direction of strong continuity (NW-SE) at right angles to that of highest variability. This pattern is also conditioned by distance, being more evident for shorter distances, as documented by results from subsequent variography and kriging (Fig. 11).

Both variograms representing the previously identified anisotropy show no stationarity for higher distances and, consequently, only the stationary component of the 


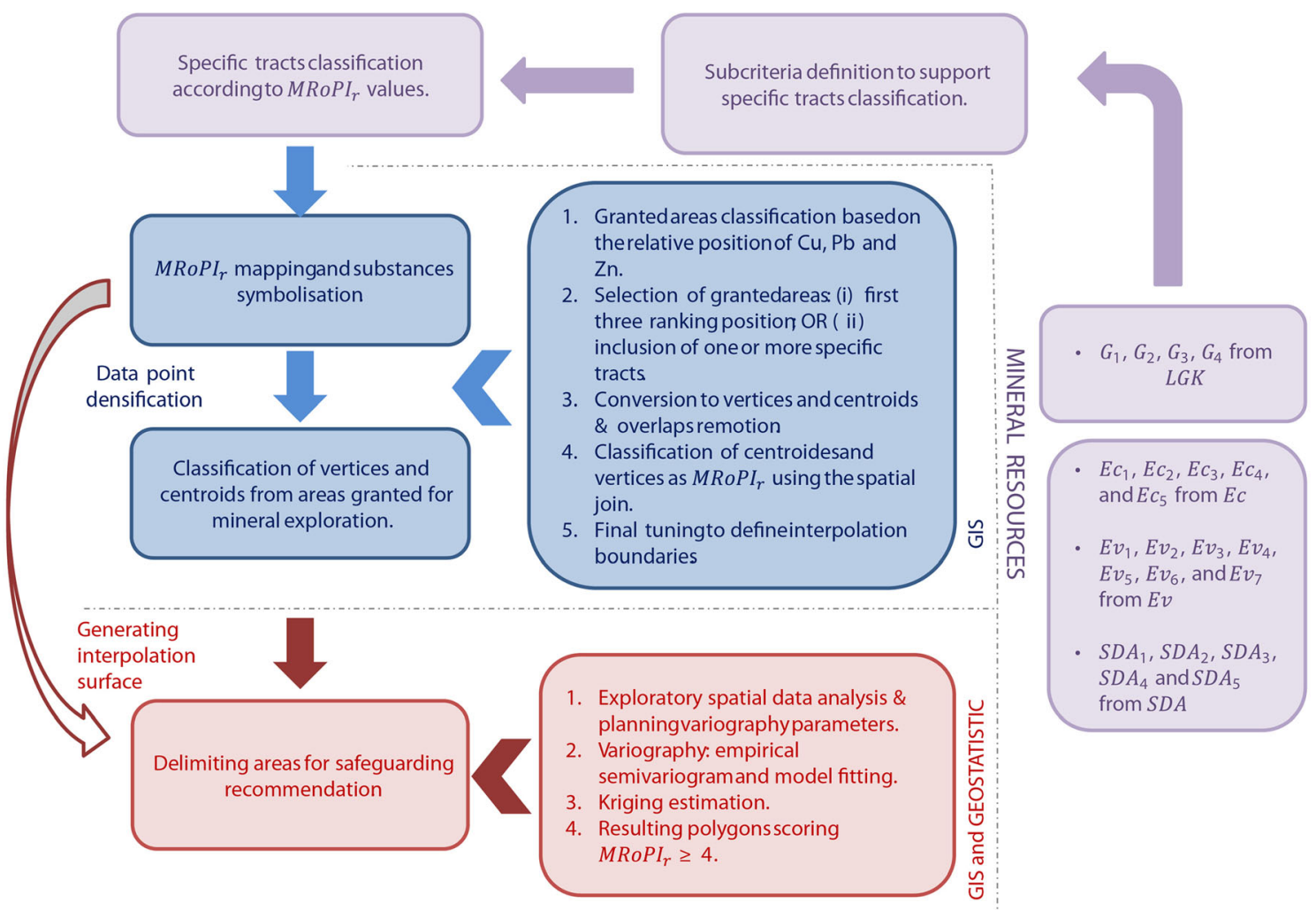

Fig. 6 General task flow scheme

variable was modelled, which has no particular impact on the results considering that the main goal of modelling is the local/regional variability. The spherical model was chosen to fit the empirical variogram taking into account that kriging estimation error must respect the fundamental condition of non-bias, which means that its mean should be zero and therefore there should be no systematic deviations of the estimated values. These deviations can be calculated by several errors as presented in the Fig. 11. In general, all the errors are relatively close to zero and just the Root-Mean-Square-Standardised Error stands above 1, but still below the recommended threshold of 2. Also, the regression function shows a good correlation between predicted and measured points. Therefore, interpolation results are enough consistent to be considered in subsequent steps of MRoPI mapping.

As previously mentioned, this approach aimed the delimitation of areas with $M R o P I_{r} \geq 4$ whose intrinsic value should support a safeguarding decision on the current and future access to "base metals" resources in Portugal mainland. The resulting map (Fig. 12) delimits a total area of $\approx 3850.30 \mathrm{~km}^{2}$ with $M R o P I_{r} \geq 4$ ( $\approx 4.33 \%$ of Portugal mainland) that includes the main Neves Corvo and Aljustrel mining areas, which are characterised by $M R o P I_{r}$ values of 8.73 and 8.19 , respectively. The superposition of this area to the Geological Map of
Portugal shows in addition an excellent correspondence with the main geological features to which those resources are related, validating independently the approach pursued. Accordingly, it stands out that the use of areas granted for mineral exploration provided a fundamental physical support to the interpolation (improving the spatial data arrangement and increasing the resolution/scale of information) and consequent robustness in the delimitation of areas that can be covered by a safeguarding decision.

The map in Fig. 12 represents also a fundamental tool in land-use planning. According to the accumulated geological evidence, this map illustrates the spatial distribution of tracts hosting the most relevant Portuguese resources of "base metals", whose sterilisation should be prevented. How then should we proceed? The first step consists in the overlapping of other layers of information to the map in Fig. 12 (or similar representations) seeking for the identification of areas of existent or latent land-related conflicts. In presence of existent land-related conflicts, it is important to separate the cases where the access to the mineral resource is already compromised due to irreversible and wrong decisions of the past, from the cases where the safeguarding measures are compatible with other land uses or where it is possible to effectively promote this compatibility. Latent land-related conflicts, on the other hand, should be evaluated on a case-by-case basis, 
Fig. 7 Spatial distribution of the 241 "base metals" mineral occurrences and resources recognised by the SIORMINP Portuguese official catalogue and categorised according to their MRoPI $_{r}$ value

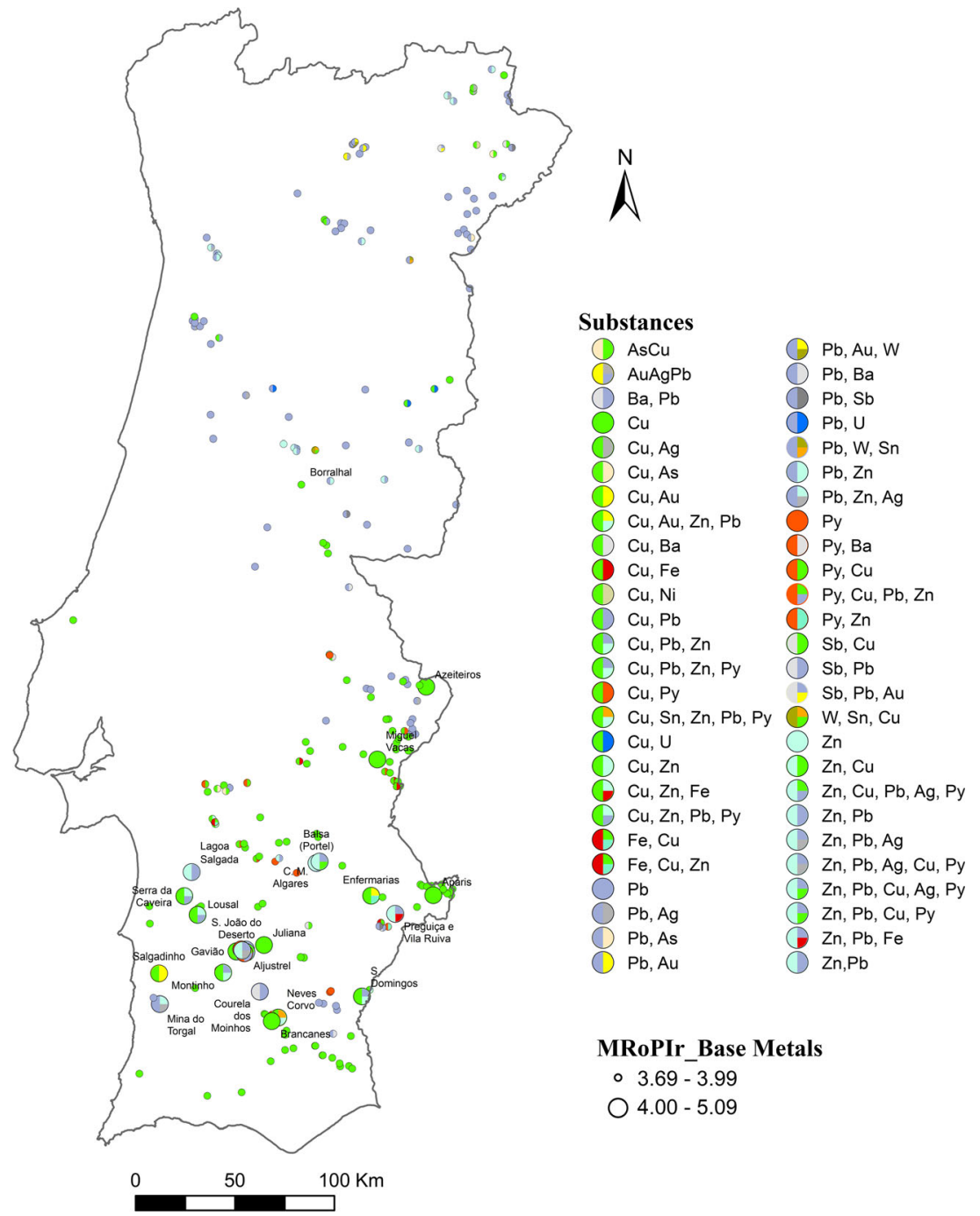

favouring always the implementation of measures to safeguard the access to areas with $M R o P I_{r} \geq 4$ without necessarily implying the exclusion of other land uses at different time scales; the main goal is to prevent the sterilisation of the mineral resource and not create artificial/administrative fences that may restrain land occupation more than necessary.

\section{Discussion}

The multi-criteria methodology here reported was tested and applied to other Portuguese mineral resources in addition to those of "base metals" after a comprehensive criteria densification for conveniently assess the $L G K$ dimension, adjusting and harmonising the information compiled in SIORMINP for each type of substance. The results so far gathered are synthetized in Fig. 13 which illustrates the spatial distribution of areas with $M R o P I_{r} \geq 4$ that, according to present-day knowledge, host the Portuguese resources of $\mathrm{W}, \mathrm{Fe}, \mathrm{Cu}-\mathrm{Zn}$ $\mathrm{Pb}, \mathrm{U}$, kaolin and ornamental stones whose current and future access should be safeguarded. These results reveal that, although arguable, the assumptions made for the empirical parameters $n$ and $m$ are plausible. The same applies to the simple approach used for the "qualitative data assessment" (QDA), taken just as 1.00 or 0.00 (see "Criteria densification used in the $\mathrm{MRoPI}_{\mathrm{r}}$ computation" section) in face of the available information, but without discard future improvements of the performed calculations when supported by a well-structured, harmonised and extensive database, suitably serving all criteria. The spatial distributions illustrated in Fig. 13 include specific tracts where active mining/quarrying works or promising prospects already exist and for which many criteria behind the $E c, E v$ and $S D A$ dimensions can be suitably evaluated, as demonstrated in the "base metals" case study; also in these cases the decision of weigh equally the $E c, E v$ and $S D A$ dimensions proved appropriate.

Similar maps to that in Figure 13, delimiting areas with $M R o P I_{r} \geq 4$ at different scales, represent one of the main frames that can be used in forthcoming land-use planning exercises. In fact, overlying other layers of relevant information, one may 


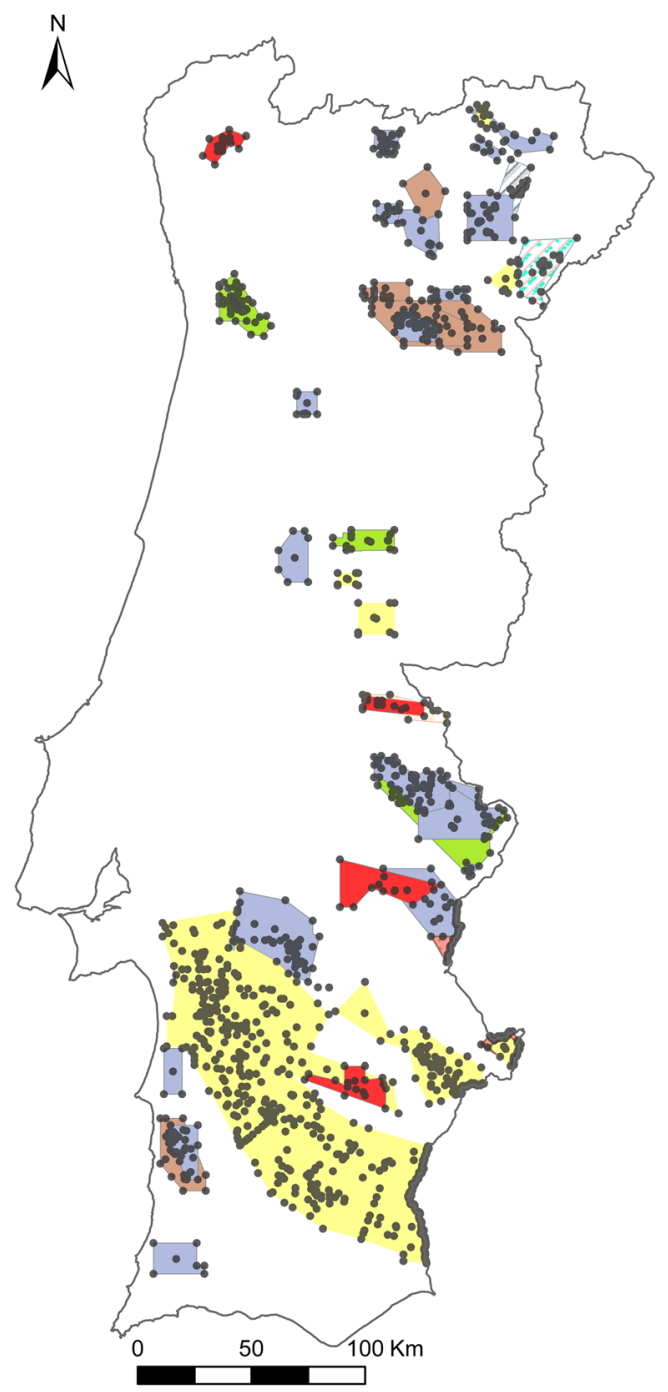

Exploration and Exploitation Contracts since 2007

$\mathrm{Cu}, \mathrm{Pb}$ or $\mathrm{Zn}$ ranking position in the contract

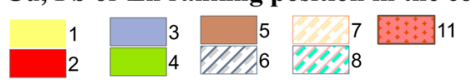

Vertices and Centroids .

Fig. 8 Spatial distribution of the areas granted since 2007 to exploration works in "base metals", according to the official information disclosed by the Portuguese Mining Authority (DGEG)

easily delimit areas where the access to mineral resources: (1) is already committed to other long-lasting intensive uses, being unrealistic to initiate any safeguarding procedure; (2) conflicts with further land-uses and/or communal interests, requesting extra science-based information and constructive discussions with all the concerned stakeholders before activate the safeguarding mechanism; or (3) does not represents matter of particular concern with current or foreseen land-uses, allowing the administrative Authorities to decide on the importance and/ or interest in applying the safeguarding procedure. In this regard, it should be emphasised again that exploration surveys should not be limited to areas safeguarded as MRoPI. These surveys are compatible with the large majority of land-uses and that restriction, not being technically defensible, is counterproductive because it prevents the test and validation of innovative models that could trigger new discoveries and increase the existent knowledge. Moreover, it should be remembered that the reported methodology is a simple tool for delimit areas hosting mineral resources of public importance, regardless of their location in urban or rural territory, protected (as consequence of other natural or cultural values) or not. The mining and land-use planning authorities should prepare the technical foundation of the safeguarding decision, cumulatively: (1) preventing and managing the land-related conflicts according to the best procedures and to the law in force on the access to land; (2) controlling over land-based resources where minerals are inevitably included; and (3) securing land rights beyond property rights for all. The final decision will always be political, but well-succeeded actions to safeguard mineral resources of public importance will be easier to implement in presence of a clear/consequential policy on mineral resources, supported by broader regulations where those resources are considered in parity with all the remaining natural resources and eco-services.

At this stage, a new question arises: if a MRoPI safeguarding decision can be merely supported by $L G K$, why should we care about $E c, E v$ and $S D A$ dimensions? The answer is simple and twofold: (1) the consideration of $E c, E v$ and $S D A$ dimensions allows to separate specific tracts where further research is needed to confirm several geological attributes and/or delimit the resource and/or demonstrate its liable exploitation from those tracts hosting mineral resources under advanced phases of evaluation or under mining/quarrying of variable intensity and continuity; and (2) the consideration of $E c, E v$ and $S D A$ dimensions allows to reinforce the need of safeguard the access to specific tracts that enclose promising prospects already subjected to comprehensive economic and environmental studies and active mining/ quarrying operations. In addition, the multi-dimensional appraisal provides also a consistent procedure to reconcile the "public importance" and the "public interest" attributes directly and subliminally implicated by the MRoPI concept, as briefly addressed in "Mineral resources of public interest and/or public importance" section. In other words, the combined use of $L G K, E c, E c$ and $S D A$ dimensions allow to address two main purposes that implicate two overlapping and coexisting, although different, issues: (1) safeguarding the future access to mineral resources, thus ensuring the supply of forthcoming generations; and (2) planning the mineral development in the short-medium term, recognising the need of assigning specific areas to exploitation activities, thus providing the minerals required henceforward for economic growth and Society welfare. Both purposes require public consent/acceptance, strengthening the role of $S D A$ dimension in appraisals of specific tracts with $M R O P I_{r} \geq 4$. Indeed, some significant connections, not necessarily straightforward, between SDA dimension, Corporate Social Responsibility 


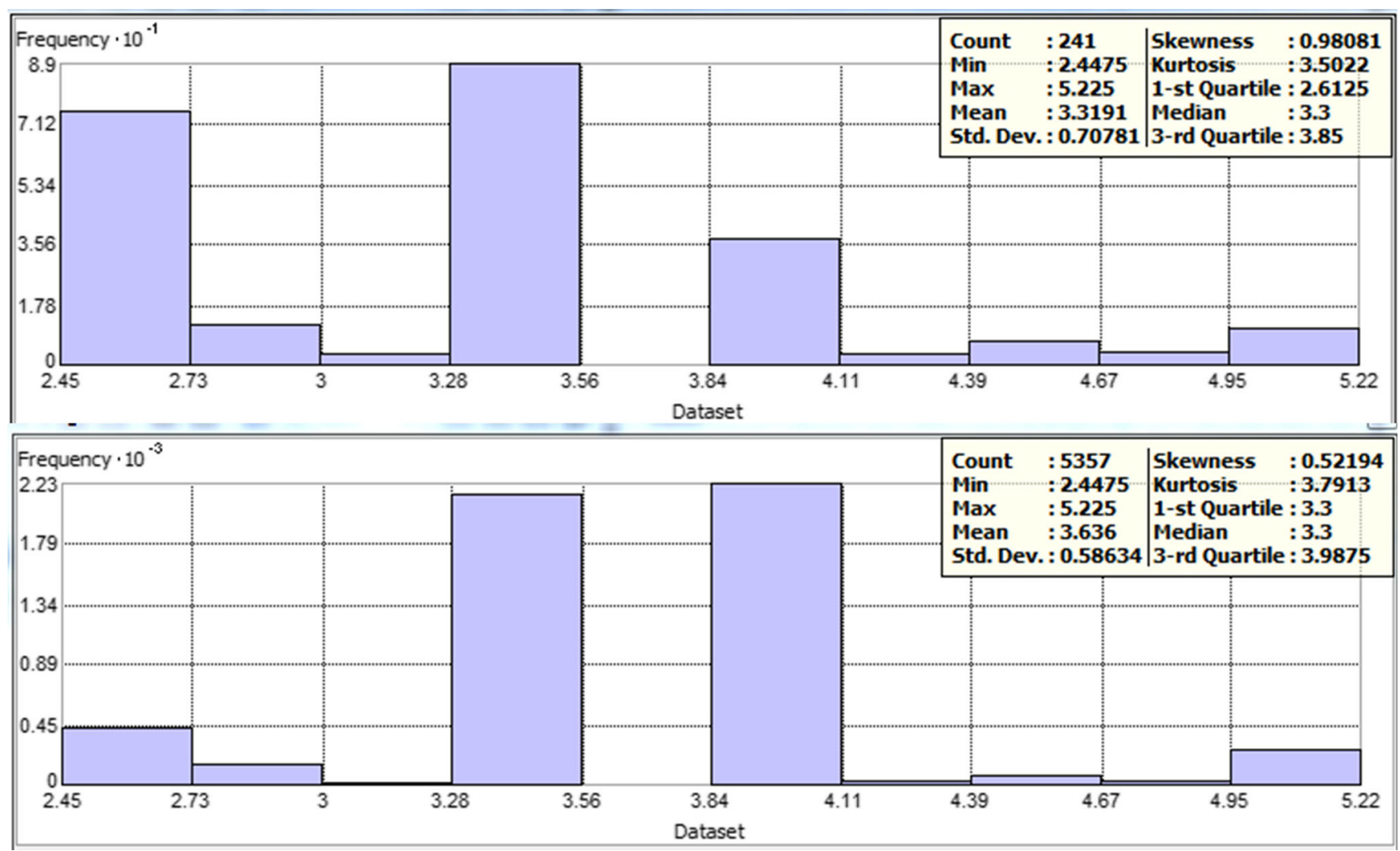

Fig. 9 Basic statistics and histograms for both populations: original 241 "base metals" specific tracts and that completed with the vertices and centroids from granted areas to exploration activities in "base metals"

(CSR) and Social Licence to Operate (SLO) can be established, demonstrating that the consent/acceptance success increases considerably if the public are engaged since early stages of the safeguarding procedure. This early engagement represents also a clever way to reduce the public awareness vulnerability to "opinion makers" that use and abuse of specific examples to fight any tentative of restore the mining sector credibility and mining development.

Given the criteria involved in the general assessment of $E c$, $E v$ and $S D A$ dimensions, their consideration together with $L G K$ allow to objectively define priorities about the safeguarding of the access/use of specific tracts scored in the interval $4 \leq M R o P I_{r} \leq 10$. This is quite relevant in reconciling practices of land-use and mineral planning, demonstrating that safeguarding the present and future access to mineral resources is not only necessary, but satisfactorily compatible with other land uses (e.g. Owens, 1997; Cowell and Owens, 1998; Cowell and Murdoch, 1999; Evans et al., 2009; Tiess, 2010; Allington et al., 2016). In fact, according to criteria definitions and statements reported in "Criteria densification used in the MRoPI $\mathrm{r}_{\mathrm{r}}$ computation" section, and in particular to the resulting $M R O P I_{r}$ categorization schematically illustrated in Figure 1, a three-level priority scheme can be proposed as follows:
(1) The safeguarding of specific tracts with $M R o P I_{r} \geq 7$ is of first priority, therefore justifying the primacy of mining/quarrying activities or detailed exploration surveys in that area over any other kind of land use.

(2) The safeguarding of specific tracts with $6 \leq M R o P I_{r}<7$ is of second priority and the land access/use should be preferentially, but not exclusively, assigned to exploration and/or exploitation works; alternative land uses are thus possible provided that they do not lead to partial or total sterilisation of the identified resources.

(3) The safeguarding of specific tracts with $4 \leq M R o P I_{r}<6$ is of third priority and the land access/use with different purposes should be planned and managed carefully, favouring the progression of exploration surveys whenever needed and avoiding circumstantial or long-lasting alternative land uses that can jeopardise further endeavours that may guide to viable mining/quarrying operations.

It is important to stress that this scheme must be applied openly, i.e. a given specific tract having $M R o P I_{r} \geq 4$ can change its level position in consecutive ranking exercises according to updated information. Similarly, persistence on exploration surveys may lead to results that could add new specific tracts to the spatial distributions or alter significantly the 
Fig. 10 Spatial distribution of the 241 "base metals" mineral occurrences (left) and the total 5357 data points (right) obtained by adding the 5116 vertices and centroids of areas granted since 2007 to exploration works in "base metals"

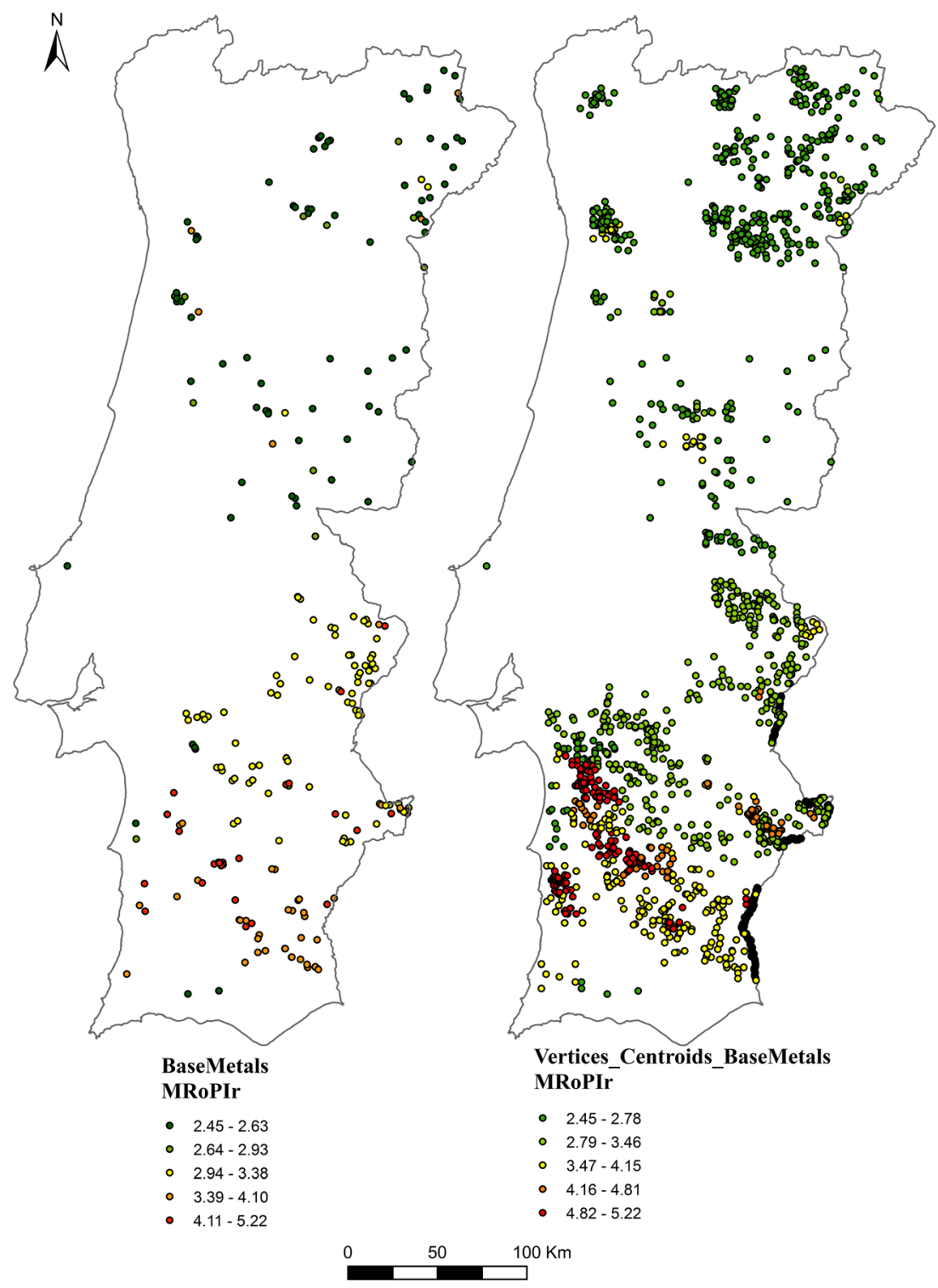

assessment accomplished in a certain date for specific tracts with $M R o P I_{r}<4$, placing them within the list of areas that should be safeguarded. This observation is of prime importance, strengthening both the importance of implement a regular revision of the MRoPI outputs and of do not confine exploration surveys to areas safeguarded as MRoPI, as recurrently stated since early sections of this work. So, the fundamental corollary of the reported methodology can be summarised as follows: the $L G K$ dimension is decisive to support a "safeguarding decision" on the current and future access to MRoPI, and the complementary Ec, Ev and SDA dimensions (if duly assessed) are important to objectively assist a verdict on the "priority and compatibility with other uses" in land-use planning exercises.

Notwithstanding the promising results obtained with the proposed methodology, three major risks are involved in its application. The first risk is intrinsically related to the high variability of some criteria and sometimes its subjective characteristics, in particular those depending on "market factors" (restraining, e.g., investments in cutting-edge solutions aiming eco-efficiency improvements) or on "circumstantial political features" that are inherent to $E c$ and SDA dimensions. The second risk is related to the available databases where the information needed to fulfil the criteria included in the methodology should rely. If too fragmented and not systematically updated by a dedicated expert team, the obtained results will be doubtful and may put in risk the intention of have a consistent MRoPI map, viewed as credible for all the agents involved in land management/planning. These former two risks can be minimised if a regular, thoroughly revision of the $M R O P I_{r}$ scores is established for all known and new specific tracts, considering up to date information. In this regard, a triennial upgrading of MRoPI maps 


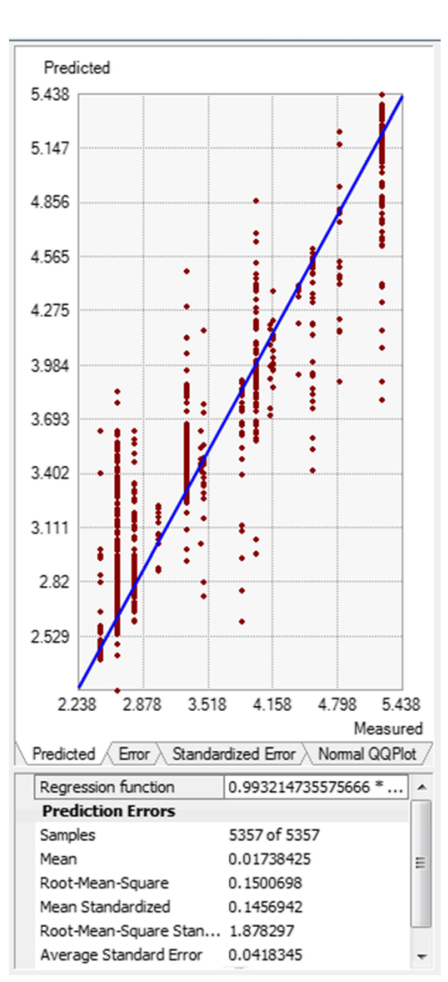

$r \cdot 10^{1}$

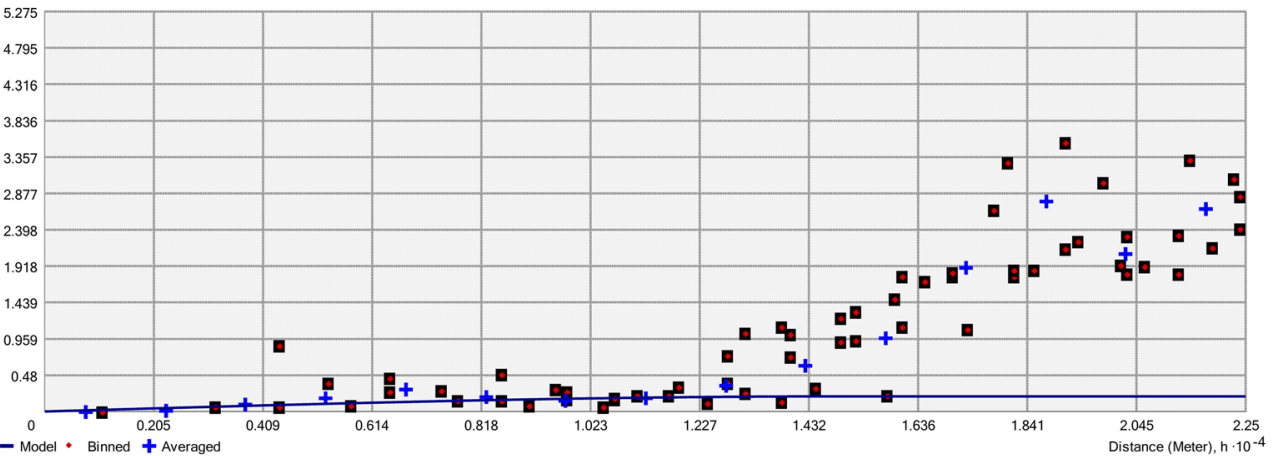

- Model $\cdot$ Binned + Averaged
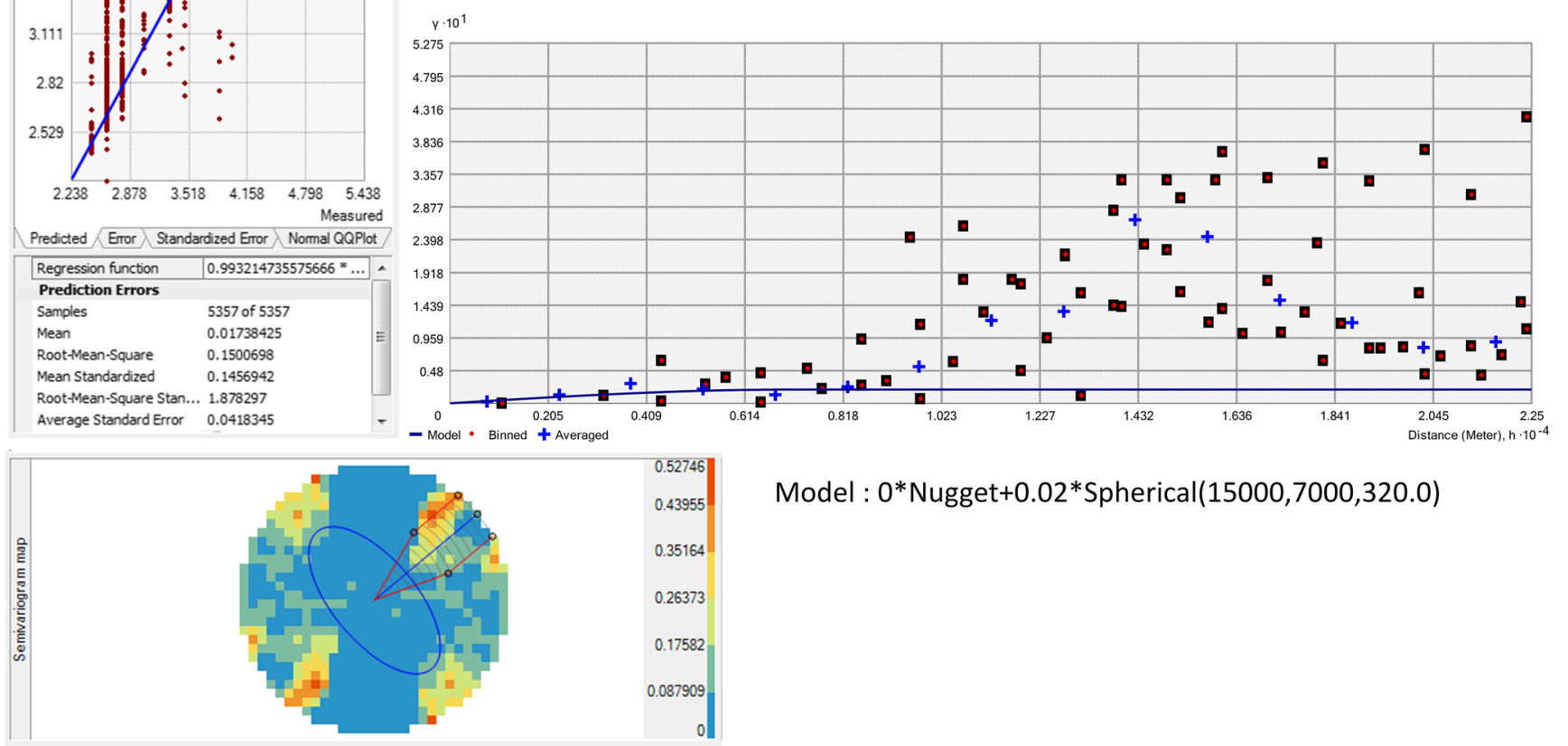

Model : $0 *$ Nugget+0.02*Spherical $(15000,7000,320.0)$

Fig. 11 Results from variography and kriging

is highly recommended, assuming that databases will be subjected to continuous improvements; this will facilitate the incorporation of updated results in the scheduled periodic revision of landuse plans at regional/national levels. The third main risk concerns the way how the $M R o P I_{r}$ algorithm can be used in routine and by whom. In fact, the calculations involved are quite simple but, if not properly handled, the final results can be disastrous, threatening all the process and creating the conditions for a generalised disbelieving about the need to safeguard the access/use of MRoPI. Consequently, the application of the proposed methodology cannot be viewed as a simple administrative act periodically (or whenever possible) launched. Instead, the application (and further refinement) of the methodology should be a matter of permanent concern of a committed and multidisciplinaryskilled team strongly connected with the group of experts responsible for the systematic upgrading of databases. In our perspective, the national land-use planning and mining authorities should lead the whole process, designating the multidisciplinary-skilled team (shared by both organisations) and providing all the means needed to its regular functioning. This team should be assisted whenever necessary by the geological surveys which will be responsible for updating the inventories and other information useful for assessing the $L G K$ dimension through a dedicated taskforce and a specific budget allocation.

Finally, it should be emphasised that there are added difficulties in fulfil currently all the criteria behind the proposed multi-dimensional methodology and, in order to overcome them, significant efforts should be made to develop harmonised databases. This is particularly demanding for several of the criteria included in the $E c, E v$ and $S D A$ dimensions. However, the development of persistent and properly targeted work will solve a considerable number of adversities in a short time range, as confirmed by the various case studies worked in Portugal. In this regard, it is important to remember again that the intended methodology does not represent a tool to perform a comprehensive survey on the economic potential and the environmental impact related to active or foreseen mining/ quarrying works in a certain specific tract, neither should stand as a way to investigate the social development and acceptance of these industrial activities. Instead, the intended 


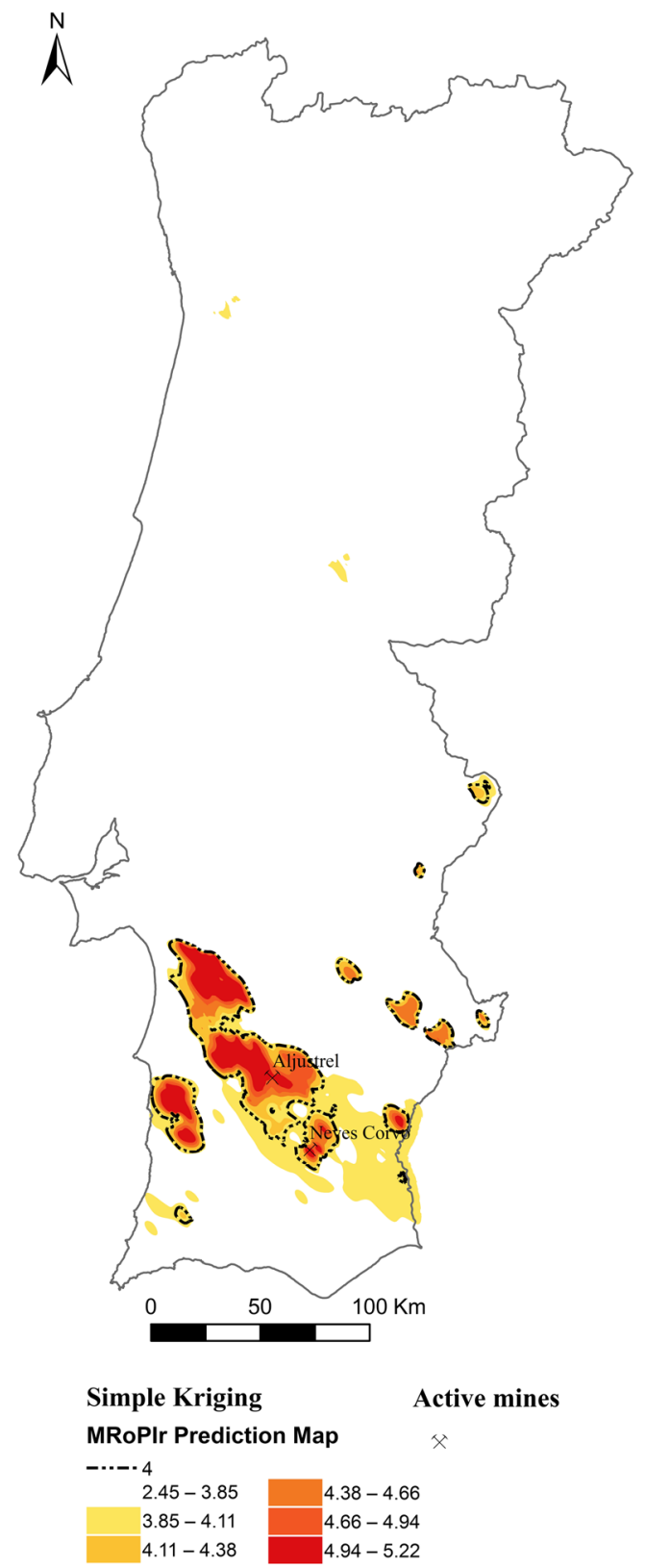

Fig. 12 Spatial distribution of areas with $M R o P I_{r} \geq 4$, hosting "base metals" resources and resulting from simple kriging interpolation; these are areas whose safeguarding should be recommended

methodology should use the available information disclosed by independent studies, handling conveniently the data to ensure acceptable levels of harmonisation and further fulfilment of the identified criteria in each complementary dimension.

\section{Conclusions}

Safeguarding the current and future access to mineral resources is one of the foremost challenges that the Society has to face pragmatically, thus mitigating some of the threats that may compromise alternative paths to its sustainable development. A wide range of plausible approaches to this issue can be implemented, depending on the perspective behind the justification used (or imposed by law) to trigger the "safeguard mechanism". The methodology proposed in this study is based on a multi-dimensional assessment of available data/information seeking for the identification of areas with promising potential to supply mineral products besides others hosting mineral resources with already demonstrated interest; all these meet the basic conditions to be classified as mineral resources of public importance (MRoPI). The assessment considers the Level of Geological Knowledge (LGK) along with the Economic $(E c)$, Environmental $(E v)$ and Social Development and Acceptance (SDA) dimensions. Different sets of independent, but complementary and variably weighed, criteria support the appraisal of each dimension, and a final score $\left(M R o P I_{r}\right)$ results from a reasonable balance between $L G K$ and $(E c+E v+S D A)$.

The methodology yields a general MRoPI categorisation that depends on $M R o P I_{r}$ and will be necessarily scattered in the $[1,10]$ range, as imposed by the scaling normalising factor. Accordingly, all possible scenarios will be constrained between the lowermost score $\left(M R o P I_{r} \approx 1\right)$, representing the lack of enough geological knowledge to support the limitation of any specific tract, and the highest score $\left(M R o P I_{r} \approx 10\right)$, ideally characterising specific tracts that host active and wellsucceeded exploitations with low environmental impacts, contributing to high levels of social development and deserving also strong public acceptance. Realistically, not all the known specific tracts can be safeguarded forever in an exclusive regime (in some settings, other natural capitals may rightly hinder mining and in the remaining cases land-use conflicts are unavoidable), so a threshold value must be used. Following the reported approach, this boundary relies exclusively on $L G K$, because $E c, E v$ and $S D A$ dimensions can only be suitable evaluated in specific tracts where active mining/ quarrying operations or promising prospects already exist; and since high levels of geological knowledge available for a specific tract offer the confidence needed to decide about the threshold value, the latter is placed at $M R o P I_{r}=4$.

Adequate $M R o P I_{r}$ mapping can also be done, interpolating within the kriging formalism and evaluating thoroughly the modelling results until achieving the final map. In this process, the use of data points representing vertices and centroids of areas granted for mineral exploration is strongly recommended. Their addition provides an essential physical support to the interpolation (contributing to an improvement of spatial data arrangement and an increase of resolution/scale of information) and consequent robustness in the delimitation of areas embraced by a safeguarding decision.

The resources of "base metals" were used to illustrate the methodology application, considering the 241 specific tracts recognised in the Information System of Portuguese Mineral 
Fig. 13 Spatial distribution of areas with $M R o P I_{r} \geq 4$ that, according to the available knowledge, host the Portuguese resources of $\mathrm{W}, \mathrm{Fe}$ and $\mathrm{Mn}, \mathrm{Cu}-$ $\mathrm{Zn}-\mathrm{Pb}, \mathrm{U}$, kaolin and ornamental stones (limestone, marble and granite) whose current and future access should be safeguarded

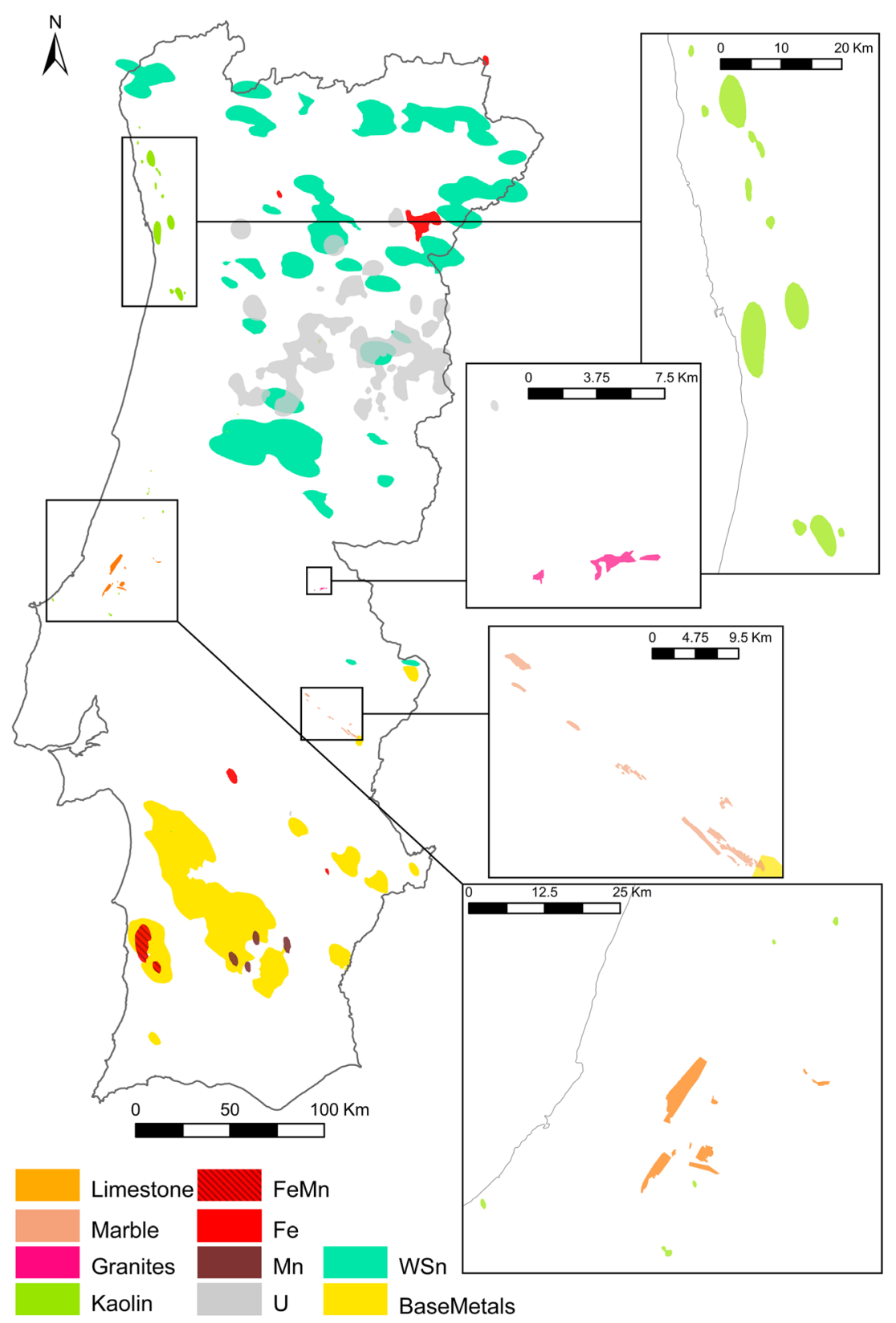

Occurrences and Resources and the 588 officially granted areas for $\mathrm{Cu}, \mathrm{Zn}$ and/or $\mathrm{Pb}$ exploration. As a result, 25 specific tracts located in SPZ and OMZ display $M R o P I_{r} \geq 4$, and the obtained scores for the main Neves Corvo and Aljustrel mining areas were 8.73 and 8.19 , respectively. The kriging prediction map for "base metals" in Portugal delimits a total area of $\approx 3850.30 \mathrm{~km}^{2}$ with $M R o P I_{r} \geq 4(\approx 4.33 \%$ of Portugal mainland), largely overlapping segments of the most promising sectors of the Iberian Pyrite Belt, that also include the prime historical and current mining centres.

The well-succeeded tests so far done suggest that the multi-dimensional MRoPI methodology here presented can be considered in workouts intended to support a "safeguarding decision" on the future access to mineral resources, if $M R o P I_{r}$ scores were subjected to a periodic and thoroughly revision in order to integrate up to date information. In these circumstances, the methodology provides also a consistent procedure to reconcile the "public importance" and the "public interest" attributes directly and subliminally implicated by the MRoPI concept.

Acknowledgements This study was funded by the MINATURA2020 project (grant agreement $n^{\circ} 642139$ ) running within the scope of the European Union's Horizon 2020 Programme for Research \& Innovation. The authors are grateful to LNEG (Laboratório Nacional de Energia e Geologia) and DGEG (Direcção Geral de Energia e Geologia) for access permission to the Portuguese mineral resources official repositories. Special thanks are due to Augusto Filipe and Daniel Oliveira, both 
from LNEG, for their significant support, fruitful discussions and sharing knowledge on the SIORMINP national catalogue. The authors also acknowledge Carlos Caxaria, Paula Dinis, Miguel Goulão, Célia Marques and Vitor Duque, members of MINATURA2020's Portuguese team, for insight discussions and relevant suggestions to the reported multidimensional methodology. The manuscript benefited from constructive comments and suggestions of the two anonymous reviewers whose work is appreciated.

Open Access This article is distributed under the terms of the Creative Commons Attribution 4.0 International License (http:// creativecommons.org/licenses/by/4.0/), which permits unrestricted use, distribution, and reproduction in any medium, provided you give appropriate credit to the original author(s) and the source, provide a link to the Creative Commons license, and indicate if changes were made.

\section{References}

Achzet B, Helbig C (2013) How to evaluate raw material supply risksan overview. Resources Policy 38:435-447

Alexander ER (2002) The public interest in planning: from legitimation to substantive plan evaluation. Planning Theory 1:226-249

Allington R, Bailey E, Demecheleer P (2016) Applications of geoscience in land-use and mineral planning; the importance of an integrated approach. Geophysical Research Abstracts 18. EGU General Assembly 2016

Arndt NT, Ganino C (2012) Metals and society: an introduction to economic geology. Springer, p 160

Arndt NT, Fontboté L, Hedenquist JW, Kesler SE, Thompson JFH, Wood DG (2017) Future global mineral resources. Geochemical Perspectives 6(1):1-171

Ashby MF (2000) Multi-objective optimization in material design and selection. Acta Mater 48:359-369

Baldi L, Peri M, Vandome D (2014) Clean energy industries and rare earth materials: economic and financial issues. Energy Policy 66: $53-61$

Batten JA, Ciner CC, Lucey BM (2010) The macroeconomic determinants of volatility in precious metals markets. Resources Policy 35: $65-71$

Behrens A, Giljum S, Kovanda J, Niza S (2007) The material basis of the global economy worldwide patterns of natural resource extraction and their implications for sustainable resource use policies. Ecol Econ 64:444-453

Binnemans K, Jones PT, Blanpain B, Gerven TV, Yang Y, Walton A, Buchert M (2013) Recycling of rare earths: a critical review. J Clean Prod 51:1-22

Bloodworth A, Gunn G (2012) The future of the global minerals and metals sector: issues and challenges out to 2050 . Géosciences 15 : 90-97

Bojarski AD, Laínez JM, Espuña A, Puigjaner L (2009) Incorporating environmental impacts and regulations in a holistic supply chains modelling. Comput Chem Eng 33:1747-1759

Burrough PA (1986) Principles of geographical information systems for land resources assessment. Geocarto International 1(3):54-54

Carranza JM, Mangaoang JC, Hale H (1999) Application of mineral exploration models and GIS to generate mineral potential maps as input for optimum land-use planning in the Philippines. Nat Resour Res 8:165-173

Chen M-H (2010) Understanding world metal prices - returns, volatility and diversification. Resources Policy 35:65-71

Costa e Silva A (2015) A indústria mineira: mudanças e tendências nos mercados de "commodities" e desafios para o futuro. Boletim de Minas 50:3-12
Cowell R, Owens S (1998) Suitable locations: equity and sustainability in the minerals planning process. Reg Stud 32:797-811

Cowell R, Murdoch J (1999) Land use and the limits to (regional) governance: some lessons from planning for housing and minerals in England. International Journal of Urban and Regional Research 23: 654-669

Davis JC (1986) Statistics and data analysis in geology. Wiley, p 646

David M (1977) Geostatistical ore reserve estimation. Elsevier, p 364

De Groot R (2006) Function-analysis and valuation as a tool to access land use conflicts in planning for sustainable, multi-functional landscapes. Landsc Urban Plan 75:175-186

Declercq FAN (1996) Interpolation methods for scattered sample data: accuracy, spatial patterns, processing time. Cartography and Geographic Information Systems 23(3):128-144

Edwards KL (2004) Strategic substitutions of new materials for old: applications in automotive product development. Mater Des 25:529533

Erdmann L, Graedel TE (2011) Criticality of non-fuel minerals: a review of major approaches and analysis. Environ Sci Pol 45:7620-7630

Erten B, Ocampo JA (2012) Super-cycles of commodity prices since the mid-nineteenth century. DESA working paper $n^{\circ} 110$, ST/ESA/ 2012/DWP/110

Evans D, Stephenson M, Shaw R (2009) The present and future use of "land" below ground. Land Use Policy 26:302-316

Filipe A (2010) Management of mineral resources (SIORMINP). VIII Congresso Nacional de Geologia, e-Terra (http://e-Terra.geopor.pt) $20,1-4$

Filipe A, Inverno CM, Oliveira DPS, Santana H, Matos JX, Farinha RJ, Carvalho J, Batista MJ, Sardinha R, Salgueiro R, Lisboa V, Machado Leite MR, Casal MJ, Martins LM, Costa LR (2010) Recursos Minerais. O Potencial de Portugal. LNEG, Lisboa, p 74

Fizaine F (2013) Byproduct production of minor metals: threat or opportunity for the development of clean technologies? The PV sector as an illustration. Resources Policy 38:373-383

Geyer R, Jackson (2004) Supply loops and their constraints: the industrial ecology of recycling and reuse. Calif Manag Rev 46:55-73

Giljum S, Behrens A, Hinterberger F, Lutz C, Meyer B (2008) Modelling scenarios towards a sustainable use of natural resources in Europe. Environ Sci Pol 11:204-216

Gleich B, Achzet B, Mayer H, Rathgeber A (2013) An empirical approach to determine specific weights of driving factors for the price of commodities - a contribution to the measurement of the economic scarcity of minerals and metals. Resources Policy 38:350-362

Glöser S, Espinoza LT, Gandenberger C, Faulstich (2015) Raw material criticality in the context of classical risk assessment. Resources Policy 44:35-46

Goovaerts P (1997) Geostatistics for natural resources evaluation. Oxford University Press, New York, p 483

Graedel TE, Barr R, Chandler C, Chase T, Choi J, Chistofferson L, Friedlander E, Henly C, Jun C, Narrar NT, Schechner D, Warren S, Yang MY, Zhu C (2012) Methodology of metal criticality determination. Environ Sci Pol 46:1063-1070

Graedel TE, Nassar NT (2013) The criticality of metals: a perspective for geologists. In: Jenkin GRT, Lusty PAJ, McDonald I, Smith MP, Boyce AJ, Wilkinson JJ (eds) Ore deposits in and Evolving Earth. Geological Society, London, Special Publications 393

Goe M, Gaustad G (2014) Identifying critical materials for photovoltaics in US: a multi-metric approach. Appl Energy 123:387-396

Hilson G (2002) An overview of land use conflicts in mining communities. Land Use Policy 19:65-73

Ho LS (2012) Public policy and the public interest. Routledge International Studies in Health Economics, p. 266

Hodges CA (1995) Mineral resources, environmental issues, and land use. Science 268:1305

Humphreys D (2010) The great metals boom: a retrospective. Resources Policy 34:1-13 
Inverno C, Díez-Montes A, Rosa C, Gascía-Crespo J, Matos J, GarcíaLobón JL, Carvalho J, Bellido F, Castello-Branco JM, Ayala C, Batista MJ, Rubio F, Granado I, Tornos F, Oliveira JT, Rey C, Araújo V, Sánchez-García T, Pereira Z, Represas P, Solá AR, Sousa $P$ (2015) Introduction and geological setting of the Iberian Pyrite Belt. In. Weilhed P (ed.), 3D, 4D and Predictive Modelling of Major Mineral Belts in Europe, Mineral Resource Reviews, 191208, doi: 10.1007/978-3-319-17428-0_9

Kesler SE, Simon AC (2015) Mineral resources, economics and the environment. Cambridge University Press

Knoeri C, Wäger PA, Stamp A, Althaus H-J, Weil M (2013) Towards a dynamic assessment of raw materials criticality: linking agent-based demand - with material flow supply modelling approaches. Science for the Total Environment 461-462:808-812

Krausmann F, Gringrich S, Eisenmenger N, Erb K-H, Harberl H, FisherKowalski M (2009) Growth in global materials use, GDP and population during the 20th century. Ecol Econ 68:2696-2705

Lam NS-N (1983) Spatial interpolation methods: a review. The American Cartographer 10(2):129-150

Massari S, Ruberti M (2013) Rare elements as critical raw materials: focus on international markets and future strategies. Resources Policy 38:36-43

Mateus A, Noronha F (2010) Sistemas mineralizantes epigenéticos na Zona Centro-Ibérica; expressão da estruturação orogénica Meso- a Tardi-Varisca. In: Cotelo Neiva JM, Ribeiro A, Mendes Victor L, Noronha F, Ramalho M (Eds.) - Ciências Geológicas: Ensino e Investigação e sua História; Volume II: Geologia Aplicada: 47-61. Associação Portuguesa de Geólogos; Sociedade Geológica de Portugal

Mateus A, Munhá J, Inverno C, Matos JX, Martins L, Oliveira DPS, Jesus A, Salgueiro R (2013) Mineralizações no sector português da Zona de Ossa-Morena. In: Dias R, Araújo A, Terrinha P, Kullberg JC (Eds), Geologia de Portugal, vol. 1, Escolar Editora, 577-619

Matheron G (1962-63) Traité de géostatistique appliquée. Mémoires du Bureau de Recherches Géologiques et Minières. Tome I, $\mathrm{n}^{\circ} 14$, Editions Technip, Paris, Tome II: Le krigeage. $\mathrm{n}^{\circ} 24$, Editions BRGM, Paris

Matheron G (1971) The theory of regionalized variables and its applications. Les Cahiers du Centre de Morphologie Mathématique, $\mathrm{n}^{\circ} 5$, Ecole des Mines de Paris, pp. 211

Mudd GM (2010) The environmental sustainability of mining in Australia: key mega-trends and looming constraints. Resources Policy 35:98-115

Nassar NT, Barr R, Browning M, Diao Z, Friedlander E, Harper EM, Henley C, Kavlak G, Kwatra S, Jun C, Warren S, Yang M-Y, Graedel TE (2011) Criticality of the geological copper family. Environ Sci Pol 46:1071-1078

Nuss P, Harper EM, Nassar NT, Reck BK, Graedel TE (2014) Criticality of iron and its principal alloying elements. Environ Sci Pol 48:41714177

Owens S (1997) Interpreting sustainable development. The case of land use planning. The political quarterly 69 , Wiley online library

Pagell M, Wu Z, Murthy NN (2007) The supply chain implications of recycling. Business Horizons 50:133-143

Peiró LT, Méndez GV, Ayres RU (2013) Material flow analysis of scarce metals: sources, functions, end-uses and aspects for future supply. Environ Sci Pol 47:2939-2947
Porter ME, van der Linde C (1995) Green and competitive. Harvard Business Review, Reprint 95507

Prior T, Wäger PA, Stamp A, Widmer R, Giurco D (2013) Sustainable governance of scarce metals: the case of lithium. Science for the Total Environment 461-462:785-791

Purba Rao DH (2005) Do green supply chains lead to competitiveness and economic performance? Int J Oper Prod Manag 25:898-916

Roelich K, Dawson DA, Purnell P, Knoeri C, Prevell R, Busch J, Steinberger JK (2014) Assessing the dynamic material criticality of infrastructure transition: a case of low carbon electricity. Appl Energy 123:378-386

Robb L (2005) Introduction to ore-forming processes. Blackwell Publishing, Oxford, $373 \mathrm{pp}$

Rosenau-Tornow D, Buchholz P, Riemann A, Wagner M (2009) Assessing the long-term supply riscks for mineral raw materials - a combined evaluation of past and future trends. Resources Policy 34:161-175

Rowe G, Frewer LJ (2004) Evaluating public-participation exercises: a research agenda. Sci Technol Hum Values 29:512-556

Rowe G, Frewer LJ (2005) A typology of public engagement mechanisms. Sci Technol Hum Values 30:251-290

Ruberts MC (2009) Duration and characteristics of metal prices. Resources Policy 34:87-102

Ruggie JG (2004) Reconstructing the global public domain - issues, actors, and practices. Eur J Int Rel SAGE Pub ECPR-Eur Consort Pol Res 10:499-531

Scholz RW, Wellmer F-W (2013) Approaching a dynamic view on the availability of mineral resources: what we may learn from the case of phosphorus? Glob Environ Chang 23:11-27

Soares A (2000) Geoestatística para as Ciências da Terra e do Ambiente. IST Press, Lisboa, p 206

Sousa AJ, Muge F (1990) Elementos de Geoestatística. LMPM, IST, p 63

Templelman E (2011) Multi-parametric study of the effect of materials substitution on life cycle energy use and waste generation of passenger car structures. Transp Res Part D: Transp Environ 16:479 485

Tiess G (2010) Minerals policy in Europe: some recent developments. Resourc Policy 35:190-198

Tornos F, Inverno CMC, Casquet C, Mateus A, Ortiz G, Oliveira V (2004) Metallogenic evolution of the Ossa Morena zone. J Iber Geol 30:143-181

United Nations, Department of Economic and Social Affairs, Population Division - World Population Prospects, the 2015 Theol Rev https:// esa.un.org/unpd/wpp/

US Geological Survey (1980) Principles of a Resource/Reserve classification for Minerals, Circular 831. A revision of the classification system published as U.S. Geological Survey Bulletin 1450-A

Veld JI, Raciborski R, Ratto M, Roeger W (2011) The recent boom-boost cycle: the relative contribution of capital flows, credit supply and asset bubbles. Eur Econ Rev 55:386-406

Vidal O, Goffé B, Arndt N (2013) Metals for a low-carbon society. Nat Geosci 6:894-896

Wrighton CE, Bee EJ, Mankelow JM (2014) The development and implementation of mineral safeguarding policies at national and local levels in the United Kingdom. Resourc Policy 41:160-170

Zhanheng C (2011) Global rare earth resources and scenarios of future rare earth industry. J Rare Earths 29. doi:10.1016/51002-0721(10) 60401-2 